\title{
Sustainable and reliable design of reverse osmosis desalination with hybrid renewable energy systems through supply chain forecasting using recurrent neural networks
}

\author{
Li, Qian; Loy-Benitez, Jorge; Nam, Ki Jeon; Hwangbo, Soonho; Rashidi, Jouan; Yoo, ChangKyoo
}

Published in:

Energy

Link to article, DOI:

10.1016/j.energy.2019.04.114

Publication date:

2019

Document Version

Peer reviewed version

Link back to DTU Orbit

Citation (APA):

Li, Q., Loy-Benitez, J., Nam, K. J., Hwangbo, S., Rashidi, J., \& Yoo, C. (2019). Sustainable and reliable design of reverse osmosis desalination with hybrid renewable energy systems through supply chain forecasting using recurrent neural networks. Energy, 178, 277-292. https://doi.org/10.1016/j.energy.2019.04.114

\section{General rights}

Copyright and moral rights for the publications made accessible in the public portal are retained by the authors and/or other copyright owners and it is a condition of accessing publications that users recognise and abide by the legal requirements associated with these rights.

- Users may download and print one copy of any publication from the public portal for the purpose of private study or research.

- You may not further distribute the material or use it for any profit-making activity or commercial gain

- You may freely distribute the URL identifying the publication in the public portal 


\section{Accepted Manuscript}

Sustainable and reliable design of reverse osmosis desalination with hybrid renewable energy systems through supply chain forecasting using recurrent neural networks

Qian Li, Jorge Loy-Benitez, KiJeon Nam, Soonho Hwangbo, Jouan Rashidi,

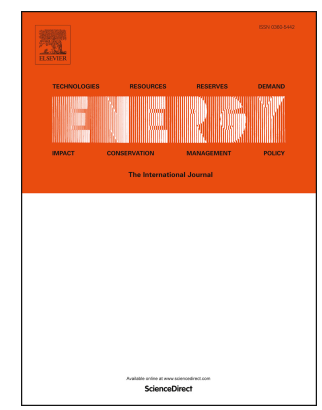
ChangKyoo Yoo

PII:

$$
\text { S0360-5442(19)30747-9 }
$$

DOI:

$$
\text { https://doi.org/10.1016/j.energy.2019.04.114 }
$$

Reference: $\quad$ EGY 15143

To appear in: Energy

Received Date: 5 December 2018

Revised Date: 28 March 2019

Accepted Date: 18 April 2019

Please cite this article as: Li Q, Loy-Benitez J, Nam K, Hwangbo S, Rashidi J, Yoo C, Sustainable and reliable design of reverse osmosis desalination with hybrid renewable energy systems through supply chain forecasting using recurrent neural networks, Energy (2019), doi: https://doi.org/10.1016/ j.energy.2019.04.114.

This is a PDF file of an unedited manuscript that has been accepted for publication. As a service to our customers we are providing this early version of the manuscript. The manuscript will undergo copyediting, typesetting, and review of the resulting proof before it is published in its final form. Please note that during the production process errors may be discovered which could affect the content, and all legal disclaimers that apply to the journal pertain. 


\section{Sustainable and reliable design of reverse osmosis desalination with hybrid renewable energy systems through supply chain forecasting using recurrent}

\section{neural networks}

Qian $\mathrm{Li}^{\mathrm{a}}{ }^{\mathrm{s}}$, Jorge Loy-Benitez ${ }^{\mathrm{a}, \S}$, KiJeon Nam ${ }^{\text {a }}$, Soonho Hwangbo ${ }^{\text {a,b }} *$, Jouan Rashidi ${ }^{\text {a }}$ and ChangKyoo Yoo ${ }^{\text {a* }}$

${ }^{a}$ Department of Environmental Science Engineering, College of Engineering, Kyung Hee University, Yongin, 446-701, Korea

${ }^{\mathrm{b}}$ Process and Systems Engineering Center (PROSYS), Department of Chemical and Biochemical Engineering, Technical University of Denmark, Søltofts Plads 229, 2800 Kgs. Lyngby, Denmark

* Corresponding Author:

ChangKyoo Yoo (E-mail: ckyoo@khu.ac.kr. Tel: +82-31-201-3824. Fax: +82-31-202-8854)

Soonho Hwangbo (soohw@kt.dtu.dk)

$\S_{\text {The first two authors contributed equally to this paper }}$

\section{Abstract:}

Renewable energy systems coupled with reverse osmosis (RO) desalination represent a great contribution to the fields of energy and sustainability. Especially in remote areas, where reliability issues associated with integrated systems result in problems of insufficient power supply or supply loss due to the intermittency of renewable sources and varying freshwater demand. This research aims to design a sustainable and reliable hybrid renewable energy system (HRES) coupled with RO desalination system (HRES-RO), considering different operational scenarios with fluctuating renewable energy supply, and changeable water demand. First, future energy supply from renewable sources, and water demand were forecasted to deal with the stochastic behavior of several variables including freshwater demand, ambient temperature, solar radiation, and wind speed by means of recurrent neural networks (RNN). Then, multi-criteria optimization was conducted using extended 
mathematical programming (EMP) with the aim of minimizing the total annual costs and greenhouse gas emission. Finally, the potential loss of power supply probability (PLPSP) was introduced as a tool to illustrate the sustainability of the proposed scenarios. The results showed that the proposed framework resulted in an HRES with optimized installation strategy using 111 photovoltaic panels and 5 wind turbines by considering three criteria (economic cost, environmental effect, and energy reliability). The designed system reduced PLPSP by $18.3 \%$ compared with the base case. Furthermore, the results demonstrated the contribution of advanced forecasting algorithms to address future uncertainties in the energy supply chain.

Keywords: Energy reliability index; Supply chain forecasting model; Hybrid renewable energy system; Multi-objective optimization; Recurrent neural network. 


\section{Introduction}

Historically, freshwater scarcity has been one of the most pertinent issues in society. Approximately two-thirds of the world's population live in areas where water scarcity occurs at least one month a year [1]. Therefore, multiple media channels have declared the seawater harvesting as a sustainable solution, since seawater is free of problems associated with territorial waters that may lead to geopolitical conflicts [2,3]. Subsequently, the production of freshwater from desalination processes seems to be a local, democratic, market efficient, and ecologically sustainable solution; particularly, for remote communities, including islands and inland countryside, such areas count with easy access to seawater or brackish groundwater [4]. Conjointly, the isolation of grid electricity represents a conflicting issue in remote areas. Nonetheless, these settlements present high renewable energy (RE) potential due to easy access to wind and solar energy sources $[5,6]$.

$\mathrm{RE}$ as a sustainable energy source plays a decisive role in modern society, being gradually implemented by more and more factories and families. The reverse osmosis (RO) desalination system powered by the RE system (RES) has emerged as a cleaner alternative on protecting the local environment. However, the RE from photovoltaic (PV) and wind sources are highly depending on the weather conditions, affecting energy stability and reducing energy efficiency to a large extent.

Designing the integration system of hybrid RES and RO (HRES-RO) system has become a hotspot among the research community. Few researchers have focused on employing numerous mathematical approaches for finding optimal designs of the HRES-RO according to different assessment indices, such as economic aspects, environmental effects, power 
reliability and social criteria [7]. The primary goal of designing a hybrid renewable energy system (HRES) is to satisfy the electricity demand from the consumer. Li et al. [8] determined the HRES size based on the relation between the meteorological variables and the electricity needed by the RO consumer; on the other hand, economic parameters for the stand-alone RES represented another optimization goal. Askarzadeh and Coelho [9] proposed an optimization model for sizing a stand-alone HRES to minimize the life-cycle costs while ensuring power supply reliability, considering the supplementary electricity from conventional energy sources (fossil fuels); the ambient pollutants serve as another frequently cited consideration. Sawle et al. [10] conducted a socio-techno-economic design of HRES with a novel partial matter factor as an index in social features.

To obtain the optimal size of an HRES, most of these researchers considered one or two design assessment criteria, which are not enough when assessing a dynamic power supply system; especially, for optimal design purposes. Additional considerations should be introduced, including the power reliability, which has been often neglected when designing an HRES; on the other hand, time-varying behavior of the power supply and demand, and availability of the RE sources. These aspects may make the RES prone to break the power supply chain, resulting in a shutdown event of the power generation system. Following, the operability of an HRES is constantly affected by numerous aspects. For example, the RE sources are mainly dependent on weather and climatic conditions (e.g., solar radiation, wind speed, temperature). Consequently, the stochastic nature of these variables, including complex fluctuations of the wind speed, and changing solar radiation intensity due to cloudiness, earth rotation, among other significant factors, results in an intermittent power 
supply [11-14]. Moreover, the power needed to operate an RO system directly depends on the dynamic freshwater demand on a daily basis, which varies due to the consumers' behavior $[8,15]$. Therefore, the integration of the HRES-RO results in a conflicting take-off that may lead to a mismatch between the power supply intermittence and the dynamic freshwater demand for the consumers $[12,16,17]$.

To tackle the issue of non-reliable RES due to external dynamic disturbances and intermittencies, several alternatives have been considered, including the long-term forecasting of the RE sources availability. Several researchers have made an effort to couple different forecasting models with energy management strategy (EMS) to optimize the RES configurations, among these methods, statistical-based forecasting techniques have been explored including the autoregressive moving average (ARMA) [18]. Progressively, the accuracy of these methods needed to be taken into account to improve the management of RES. Huang and Boland [19] compared the prediction accuracy of solar power, wind power, and hybrid power by using a coupled autoregressive and dynamic system (CARDS) model. Adaptively, with the growth of artificial intelligence (AI) algorithms becoming increasingly popular, they have dabbled into the EMS field. Gupta et al. [20] optimized a standalone small HRES based on artificial neural networks (ANN) technique for solar radiation and wind speed prediction. However, most of the studies devoted to predicting the energy supply give a fixed value of the energy load, resulting in a considerable time lag that deteriorates the significance of the forecasting model into the EMS.

Modern renewable energy plants have adopted long-term forecasting methods to report future power output sequences ahead [13]. Therefore, several analyses based on forecasting 
models over the RE sources availability, and freshwater demand result useful for optimal designing, planning, and scheduling a supply chain-driven HRES [21]. Withal, the system can anticipate the power load based on seasonal patterns and unexpected events. Deep-learning based techniques are becoming increasingly popular, especially for advanced forecasting algorithms like the recurrent neural network (RNN) architectures, which have the potential to represent some computing structures in a more concise way by using feedback connections, addressing the temporal relationship of their inputs by maintaining an internal state, indicating their capability to learn patterns in temporal order [22,23]. With these aspects considered, coupling HRES-RO system with accurate forecasting data would allow the system to anticipate the availability of the RE sources and the dynamic freshwater demand, generating a realistic supply chain that foresees the shortage events when the demand cannot be met.

In this context, this study aims to couple an RNN-driven forecasting model for the freshwater supply chain and renewable source availability to assess many aspects of the HRES-RO integration, including the power reliability and costs incurred by the system. The main contributions of this paper are as follows:

- Different RNN-based forecasting structures to profile patterns of the different HRES-RO components information, i.e., freshwater demand, wind speed, solar radiation, and ambient temperature, with high time resolution.

- An extended mathematical programming (EMP) is employed to minimize the environmental effects based on the greenhouse gas (GHG) emissions and total annual costs (TAC) of HRES; moreover, several scenarios using are introduced for purposes of 
comparison, including the forecasted cases, i.e., showing the behavior of the HRES-RO system coupled with forecasted supply chain components, and base cases which illustrate the HRES-RO system neglecting the anticipation of the supply chain components.

- A power reliability index was utilized to evaluate the capacity of the HRES considering the potential shutdown time to satisfy the power demand for the RO system. The reliability is compared among the forecasted and base cases, demonstrating that the anticipation of uncertain availability of the RE source allows the adequate management of energy supply into the RO system.

\subsection{Literature review}

Over the past decades, the integration of HRES-RO has become increasingly popular among the research community. Over the past decade, several investigations have been devoted to combining different RE sources and devices to satisfy the power demand from the RO desalination system driven by RE sources like PV [17,24,25], wind [26], and hybrid renewable energy (HRE) sources $[8,12,27]$, and the coupling of HRE with battery storage systems (BSSs) $[28,29]$. The variability and intermittency are the domain features of RE, which represent a deficiency in the continuous power output; therefore, to overcome this disadvantage, researchers found pertinent the optimization of the energy efficiency from multi-aspects of RES. Three optimization goals are most mentioned. Firstly, the accurate estimation of the electricity supply and demand relationship is an initial step in the design of an HRES-RO system; thus, optimization techniques in forecasting procedure can increase the prediction accuracy and reduce the prediction time [30]. Furthermore, several investigations have been conducted to enhance the energy utilization efficiency of HRES via different EMS. 
Another challenge in the integration HRES-RO system is designing and sizing the components of the system. In this aspect, multi-objective optimization (MOO) methods are normally implemented to achieve numerous requirements. Generally, the optimization method in an HRES can be divided into three classes, heuristics-based approach, simulation and sampling techniques, and other optimization software [31,32]. A great portion of the recent investigations appoints to the optimization of the HRES-RO system for the design and sizing as emerging EMS; a summary of current studies regarding this issue is listed in Table 1.

In this context, numerous tools have been developed to facilitate the analysis of RES. The HOMER software, standing for Hybrid Optimization Model for Multiple Energy Resources, is the most prevalent optimization tool for designing HRES with considerable merits, such as user-friendly, easy investigation of numerous energy sources, and very detailed results for analysis and evaluation. HOMER is good at solving the engineering and economics work due to the interconnection of three powerful tools: simulation, optimization and sensitivity analysis [33-35]. Despite the simplicity performed by this software, the algorithms are encapsulated, making it difficult to modify the codes for specific cases. Further, simulation and sampling techniques have been introduced as well, including the simulated annealing (SA) [36], Hammersley sequence sampling (HSS) [37], and Monte Carlo simulation [38], which are based on probabilistic theory to conduct a rough global optimal solution of a given problem; these techniques are the most commonly used in designing and optimizing the sizing of HRES. 
The Heuristics-based approach is established by a trial and error concept to obtain the adaptable solution of a complex optimization problem, and it can be subdivided into an AI approach and conventional approach. With the rapid development of AI techniques, more sophisticated algorithms have been implemented in the optimization of HRES in recent years, such as genetic algorithm (GA) [17,39], particle swarm optimization (PSO) [40], fuzzy logic [41], ANN [42,43], among others. The advantage of these methods is that more accurate optimal solutions can be obtained in a relatively short time. Inspired by the biological evolution and natural selection, GA is commonly used in the design of HRES with MOO tasks by generating high-quality solutions on bio-inspired operators [44]. Similar to the GA, PSO is also a bionic algorithm, inspired by the social behavior of a bird flock or fish school [45]. Fuzzy logic methods are widely used in EMS and control architectures in HRES based on vagueness and imprecise information from human experience. Following, the conventional optimization approach is based on energy balance between supply and demand, such as linear programming [46,47], graphical analysis [8], and so on. The linear programming remains a powerful and valuable technique which is implemented in this study by establishing the simple but intuitionistic relation between power supply and demand. 
Table 1. Summary of recent optimization methods for the design of the HRESs.

\begin{tabular}{|c|c|c|c|c|}
\hline Ref. & System components & Methods & $\begin{array}{l}\text { Optimization } \\
\text { goals }\end{array}$ & Ren \\
\hline $\begin{array}{l}\text { Kaboli et al. } \\
2016[48]\end{array}$ & $\begin{array}{l}\text { Electricity energy } \\
\text { consumption }\end{array}$ & $\begin{array}{l}\text { Artificial } \\
\text { cooperative } \\
\text { search }\end{array}$ & Forecasting & $\begin{array}{l}\text { A mathematically formula to show the influence of socio-economic } \\
\text { indicators on Iran's energy consumption. }\end{array}$ \\
\hline $\begin{array}{l}\text { Kaboli et al. } \\
(2016) \text { [49] }\end{array}$ & $\begin{array}{l}\text { Electricity power } \\
\text { consumption }\end{array}$ & $\begin{array}{l}\text { Gene expression } \\
\text { programming } \\
\quad(\text { GEP })\end{array}$ & Forecasting & $\begin{array}{l}\text { This study deals with estimation of electricity demand of Iran on the basis } \\
\text { of economic criteria using a genetic-based approach called Gene } \\
\text { Expression Programming (GEP) as an expression-driven approach. }\end{array}$ \\
\hline $\begin{array}{l}\text { Gupta et al. } \\
\text { [20] }\end{array}$ & $\begin{array}{l}\text { Wind speed and solar } \\
\text { radiation }\end{array}$ & ANN & Forecasting & $\begin{array}{l}\text { A case study was used for demonstrating the performance of } \mathrm{BBO} \\
\text { optimization algorithm along with forecasting effects. }\end{array}$ \\
\hline $\begin{array}{l}\text { Dolara et al. } \\
\text { (2015) [42] }\end{array}$ & $\begin{array}{l}\text { Power generated } \\
\text { from PV plant }\end{array}$ & ANN & Forecactin & $\begin{array}{l}\text { A new hybrid method called Physical Hybrid Artificial Neural Network } \\
\text { (PHANN) based on an Artificial Neural Network (ANN) and PV plant } \\
\text { clear sky curves is proposed and compared with a standard ANN method. }\end{array}$ \\
\hline $\begin{array}{l}\text { Cheng and } \\
\text { Lin (2015) } \\
{[38]}\end{array}$ & $\begin{array}{l}\text { PV-wind-diesel-ener } \\
\text { gy storage }\end{array}$ & Monte $\mathrm{Ca}$ & System design & $\begin{array}{l}\text { The optimal design of HRES is consider the total cost of both equipment } \\
\text { installation, power generation, allocation and transmission. }\end{array}$ \\
\hline $\begin{array}{l}\text { Chen et al. } \\
\text { (2017) [37] }\end{array}$ & Wind-solar-fuel cell & $\begin{array}{l}\text { Hammersley } \\
\text { Sequence } \\
\text { Sampling (HSS) }\end{array}$ & Size optimization & $\begin{array}{l}\text { A multi-objective optimization framework based on cost, electricity } \\
\text { efficiency and energy supply reliability models were conducted. } \\
\text { Advanced } \varepsilon \text {-constraints method based on HSS was employed in the } \\
\text { multi-objective optimization of the hybrid DG system. }\end{array}$ \\
\hline O. Ekren and & PV-wind-battery & Simulated & Size optimization & To determine the PV size, wind turbine rotor swept area, and the battery \\
\hline
\end{tabular}




\begin{tabular}{|c|c|c|c|c|}
\hline $\begin{array}{l}\text { B.Y. } \quad \text { Ekren } \\
(2010)[36]\end{array}$ & & Annealing & & capacity, the objective function is the minimization of the HRES total cost \\
\hline $\begin{array}{l}\text { Bordin et al. } \\
(2017)[46]\end{array}$ & PV-bettery & $\begin{array}{l}\text { Linear } \\
\text { programming }\end{array}$ & EMS & $\begin{array}{l}\text { he main contribution of this study is developing a methodology to include } \\
\text { battery degradation processes inside the optimization models, through the } \\
\text { definition of battery degradation costs. }\end{array}$ \\
\hline $\begin{array}{l}\text { Amrollahi } \\
\text { and Bathaee } \\
(2017)[51]\end{array}$ & $\begin{array}{l}\text { PV-wind-energy } \\
\text { storage system }\end{array}$ & $\begin{array}{l}\text { Linear } \\
\text { programming }\end{array}$ & Size optimization & $\begin{array}{l}\text { To reduce the mismatch between the generation and consumption profiles } \\
\text { by time shift and schedule of dispatchable loads. } \\
\text { The effect of demand response utilization of loss of generated energy } \\
\text { reduction is studied. }\end{array}$ \\
\hline $\begin{array}{l}\text { Rajbongshi } \\
\text { et.al. (2017) } \\
\text { [35] }\end{array}$ & $\begin{array}{l}\text { PV-biomass } \\
\text { gasifier-diesel and } \\
\quad \text { grid }\end{array}$ & $\begin{array}{l}\text { HOMER } \\
\text { software }\end{array}$ & System design & $\begin{array}{l}\text { Optimization of the HRES configuration for different load profiles is } \\
\text { conducted. } \\
\text { The cost of energy is calculated for different peak load, energy demand } \\
\text { profiles and grid availability. }\end{array}$ \\
\hline $\begin{array}{l}\text { Nag and } \\
\text { Sarkar } \\
(2018)[34]\end{array}$ & $\begin{array}{l}\text { solar-wind-hydrokine } \\
\text { tic-bioenergy }\end{array}$ & $\begin{array}{l}\text { HOMER } \\
\text { software }\end{array}$ & $S$ & $\begin{array}{l}\text { Optimized results are evaluated considering total net present cost, cost of } \\
\text { energy, annual electric generation, renewable fraction and } \mathrm{CO}_{2} \text { emission. }\end{array}$ \\
\hline $\begin{array}{l}\text { Chauhan and } \\
\text { Saini (2016) } \\
\text { [33] }\end{array}$ & $\begin{array}{l}\text { solar-micro } \\
\text { hydro-biomass-wind }\end{array}$ & $\begin{array}{l}\text { HOMER } \\
\text { software }\end{array}$ & $y$ & $\begin{array}{l}\text { A load shifting based DSM (demand side management) strategy has been } \\
\text { suggested in the paper for energy management of the considered HRES. }\end{array}$ \\
\hline $\begin{array}{l}\text { Kamjoo et al. } \\
(2016) \text { [39] }\end{array}$ & PV-wind-battery & GA & Size optimization & $\begin{array}{l}\text { Two objectives considered, minimum system total cost and maximum } \\
\text { reliability. } \\
\text { Chance Constrained Programming method is proposed to address the } \\
\text { uncertainties in renewable resources. }\end{array}$ \\
\hline $\begin{array}{l}\text { Esfahani and } \\
\text { Yoo (2016) } \\
{[17]}\end{array}$ & PV-RO & $\mathrm{G}$ & Size optimization & $\begin{array}{l}\text { Freshwater pinch analysis (FWaPA) is proposed for retrofitting the PV-RO } \\
\text { system. }\end{array}$ \\
\hline
\end{tabular}




\section{Materials and methods}

\subsection{HRES-RO system configuration}

Figure 1 illustrates the fundamental diagram of designing the HRES-RO system to provide fresh water to satisfy consumer demand. The design of the HRES system is based on the forecasted weather data solar radiation, ambient temperature, and wind speed and water demand data. The forecasting procedure is shown in Fig. 1(a) according to RNN technology with two different memory cells (to obtain the predicted data based on the historical data). Then, the forecasted data were used as the input values to design the HRES. In the present study, the freshwater production is conducted through an HRES-RO system depicted by a flow diagram shown in Fig. 1(b). The HRES-RO consists of PV panels and wind turbines for green electric power generation. This power is delivered to an RO desalination system for freshwater production to meet consumers' demand. Furthermore, a BSS is considered as well to increase the stability of the power supply. This system was charged by the HRES when surplus electricity exists, and it was discharged when an electricity deficiency occurred due to the HRES intermittency. The deficiency gap between the electricity delivered from the HRES-BSS and the electricity needed from the RO system was fully filled by the conventional power grid.

During the development of this study, the following considerations were assumed [8]:

- The RO desalination system operates with alternating current (AC) electricity. The RO system directly used electricity from wind turbines, and a conventional power grid. However, an inverter was needed to convert direct current (DC) to AC when RO accepts electricity from the PV panels. 
- The BSS was capable of storing only the DC form of electricity. The BSS can directly use the electricity from PV panels. However, a converter was used to convert electricity from wind turbines into DC form for storage in the BSS.

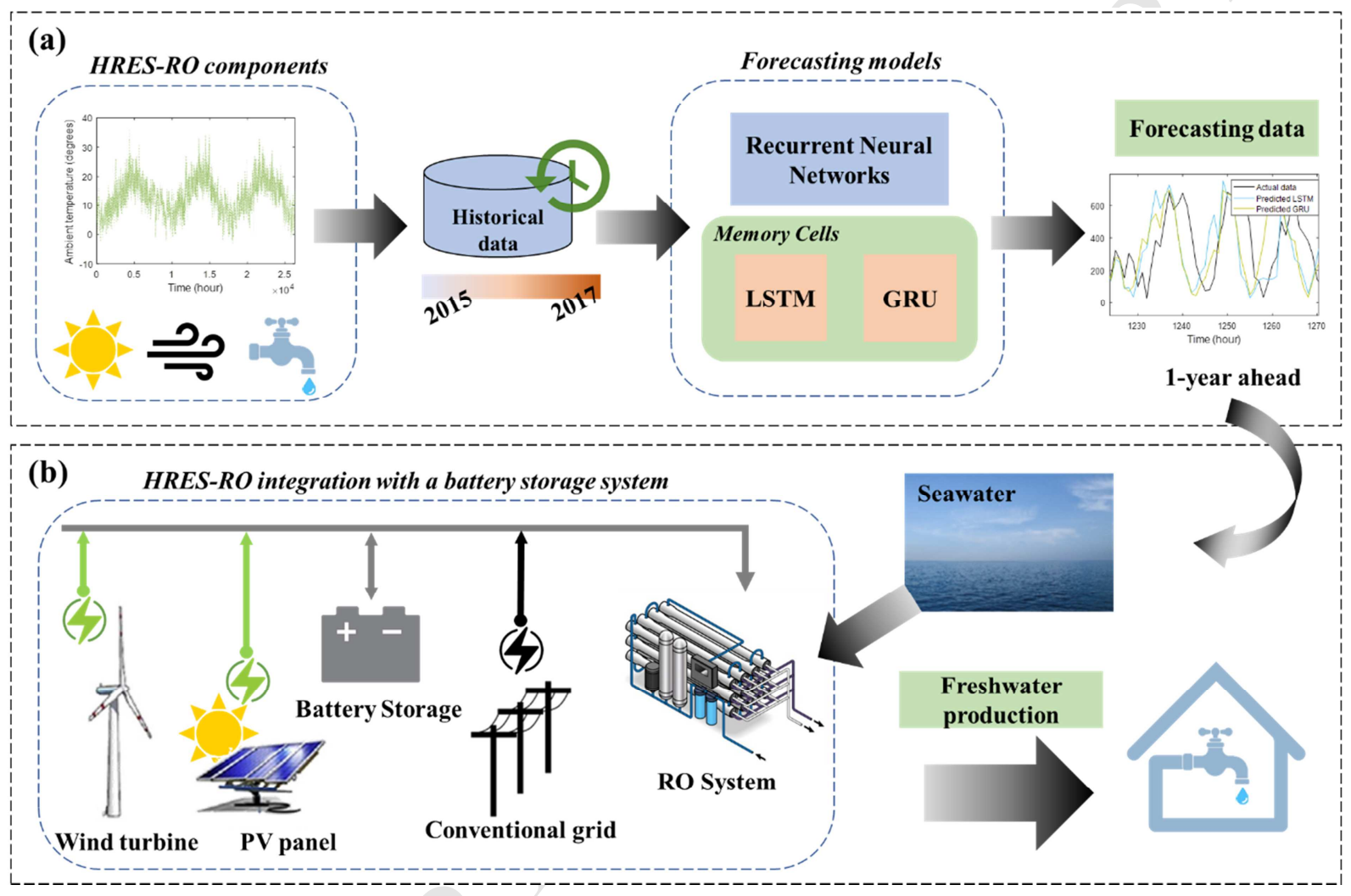

Fig. 1. The framework of the supply chain forecasting model for the HRES-RO system. (a) The forecasting procedure using RNN to predict the weather conditions (temperature, solar radiation, and wind speed), and water demand data. (b) An integrated HRES-RO electricity supply procedure using forecasted data.

\subsection{Data description}

The experimental data of ambient temperature, solar radiation, and wind speed were extracted from the London air quality network website. This information was used to 
calculate the output power from the HRES. On the other hand, water consumption data were gathered from the London home office in the UK. Hourly data from 2015 to 2017 were gathered to implement the analysis in this study. To this end, several long-term predictive models were conducted based on the historical data for a whole year dataset (2018), where the raw data of the four major variables of solar radiation, ambient temperature, wind speed, and water demand are shown in Fig. S2. Here, two variables of the ambient temperature and solar radiation have a seasonal pattern, which shows an increasing trend during hot seasons and decreasing trend during cold seasons. On the other hand, the wind speed lacks a specific pattern due to several unpredictable events and variables affecting its variability (e.g., air pressure, centripetal acceleration, earth's rotation).

\subsection{Algorithm for assessing the optimal HRES system}

The goal of this study was to develop an optimization algorithm to find the optimal scale of an HRES to meet the electricity demand for an RO desalination system considering future uncertainties. The energy reliability of the proposed algorithm combined with a forecasting model was estimated; then, a base case procedure was developed without the consideration of future variations was developed, and its reliability was also computed for purposes of comparison. Fig. 2 shows the optimization algorithm carried out in this study.

In the proposed algorithm, forecasting models were implemented as the first step to obtain future data sequences related to the HRES-RO operability. The forecasting was conducted for several variables including the ambient temperature, solar radiation, wind speed, and water demand. Second, the amount of electricity generated from PV panels and 
wind turbines was calculated based on a mathematical model for the solar and wind systems. The amount of electricity needed from the RO system was estimated by the daily water consumption, in such a way that it indicates how much freshwater needs to be produced from seawater, and the electricity ratio that covers the desalination process. Third, multi-objective functions with two criteria were defined to determine the optimal sizes of the HRES. The purpose of the optimization was to minimize the total annual cost of the HRES and the total GHG emissions from the electricity grid supplied by a conventional power plant and HRES system. Then, a power supply algorithm was developed considering the power losses during the electricity transmission process to optimize the supply chain. Finally, an analysis of energy reliability under future uncertainties was conducted. In addition, a new energy reliability index was introduced considering the shutdown times of RES due to system failure events. On the other hand, for the base case, a similar process was conducted neglecting the forecasting model; therefore, further considerations based on historical data were no longer provided, including the optimal HRES size and dynamic variance of real conditions.

In this study, the planned optimization problems were solved by means of EMP. EMP is an extension of algebraic modeling languages that facilitate the automatic reformulation of new model types as models in more established mathematical programming classes, allowing them to be solved by mature solver algorithms. These algorithms are commonly used to solve Nash games and equilibria, bi-level programs, disjunctive programs, and stochastic programs; in this particular study, the power supply processes are considered to be a disjunction problem in this study. Computationally, the GAMS software was implemented using the EMP solver to solve the disjunction program problem [52]. Moreover, the eps-constraint method 
[53] was employed for solving the multi-objective function in GAMS.

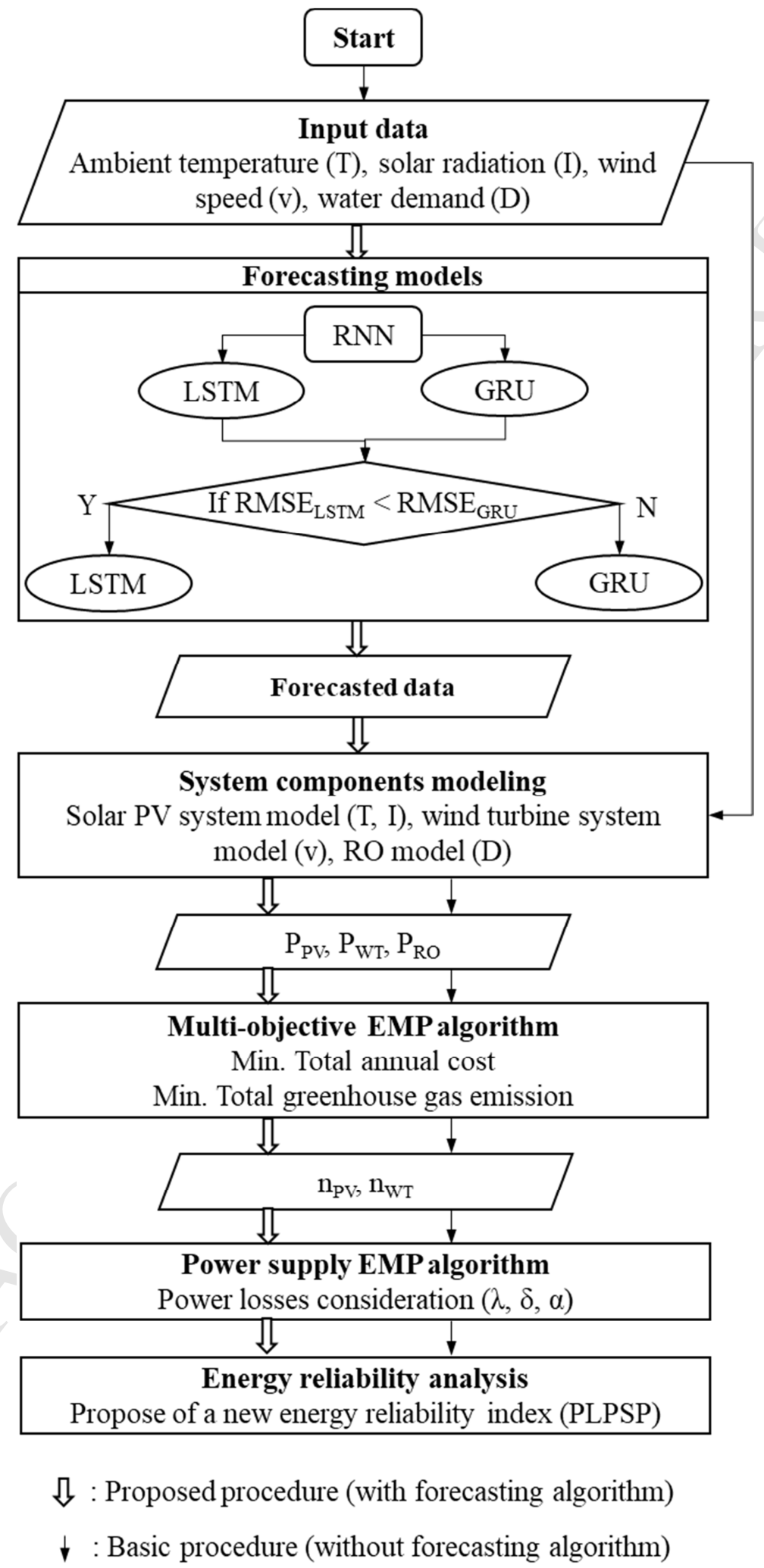

Fig. 2. The algorithm of the optimal HRES-RO design using multi-objective EMP and energy 
reliability.

\subsection{The forecasting procedure}

Persistent intermittent failures in the power supply are expected due to the stochastic nature of the PV and wind energy sources (i.e., solar radiation, temperature, and wind speed). Moreover, the freshwater demand can be understood as the energy required for RO operation. Forecasting these variables is presented as a strategy to overcome the mismatch between the renewable energy sources and the energy demand since an early signal of these variables allows adjustment of the supply/storage functionality of the HRES-RO system and the BSS.

An RNN with a memory cell architecture was selected for forecasting; these structures, in particular, take advantage of the data autocorrelation and tend to control the data propagation within the network to process sequences, retain important features and memorize patterns. Then, multiple sequences of predicted values can be obtained using a moving window algorithm. In this study, long short-term memory (LSTM) and gated recurrent unit (GRU) structures were implemented and compared to select the most accurate forecasting architecture. The two-thirds parts of the available measurements were selected for the training set, while the rest was used for the testing phase of the RNN structures as described in section 1 of the Supplementary Information (SI). Computationally, the forecasting models were implemented using the Keras library in Python. The standard architecture consists of an input layer with a single neuron, a first hidden layer with 50 neurons, a second hidden layer with 100 neurons, and finally, an output layer with a single neuron.

The moving window principle complements the RNN structure to build multiple 
sequential forecasted datasets. This method has been implemented in several investigations to predict time series data and consists of the construction of a moving window, which takes previous output as input to forecast future data points [22,54,55]. First, the dataset for each component is divided into training (70\%) and testing (30\%) sets. Second, the window size is defined by several look-back data points; on the other hand, the sequence length is defined by the number of time steps yet to be predicted. Then, at each time step, the oldest entry goes off the rear of the window, and the prediction is appended for the next time step at the front of the window. Finally, the windows are slowly self-constructed with predictions until the window is full of predicted values.

For this study, the window size and the sequence length were set to both be 24 hours; then, the prediction horizon was set to one whole year. To fulfill the operative year with forecasted data points, a recursive strategy is implemented in this study. For each univariate time-series variable, suppose that $K$ is the length of the window size, and $O$ is the sequence length. Suppose that $X=\left\{x_{1}, x_{2}, \ldots, x_{K}\right\}$ represents the input set, $\hat{X}=\left\{\hat{x}_{K+1}, \hat{x}_{K+2}, \ldots, \hat{x}_{K+O}\right\}$ is the output set, and $\hat{x}=\hat{f}(x)$ is the predictive model. Then, the recursive strategy is shown in Eq. (1).

$$
\hat{x}_{K+i}=\left\{\begin{array}{ccc}
\hat{f}\left(x_{K}, x_{K-1}, \ldots, x_{1}\right) & ; \quad i=1 \\
\hat{f}\left(\hat{x}_{K+i-1}, \ldots, \hat{x}_{K+1}, x_{K} \ldots, x_{i}\right) & ; \quad 1<i \leq K \\
\hat{f}\left(\hat{x}_{K+i-1}, \hat{x}_{K+i-2}, \ldots, \hat{x}_{i}\right) & ; \quad P<i \leq O
\end{array}\right.
$$

where $i$ represents an hourly time-step. Finally, the root mean square error (RMSE) was used to compare and select the most suitable predictive method. Fig. 3 depicts a simplified schematic of the moving window procedure with a recursive strategy for predicting the time series dataset. 


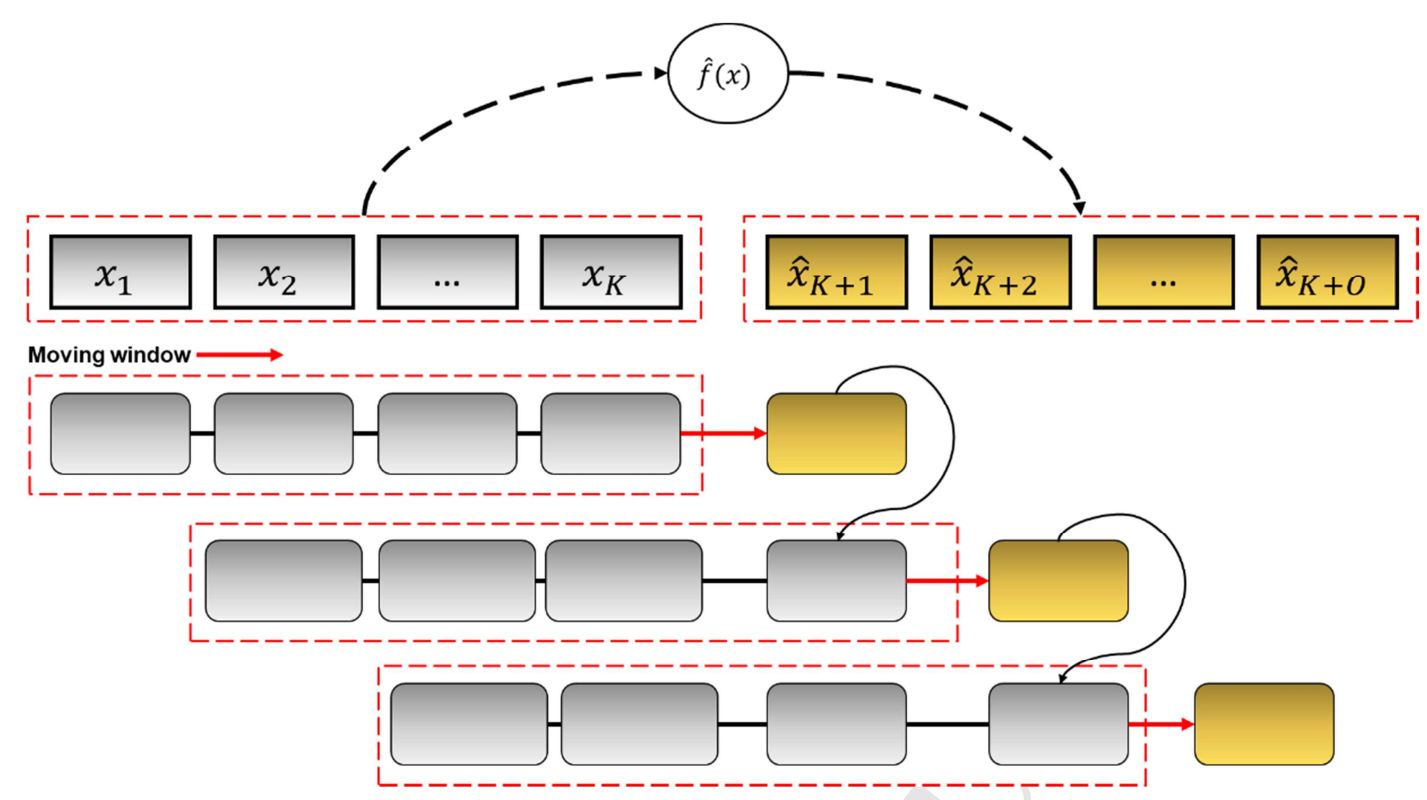

Fig. 3. A simplified schematic for the moving window with a recursive strategy for the forecasting procedure.

\subsection{Energy reliability index}

The size of the HRES is designed considering economic and environmental effects by using the mathematical model, as shown in section 3. Several indices are broadly utilized to estimate the performance of the designed HRES [56-58]. Here, the reliability of the power supply was widely used to evaluate the degree of reliability of the power supply system [59]. In addition, the probability of power loss was defined as the proportion of the HRES that is unable to satisfy the electricity demanded by the consumer. In this study, the energy reliability index was used as one criterion to select the optimal combination of equipment in an HRES to meet the power demand from the RO desalination system.

The loss of power supply probability (LPSP) is a useful energy reliability index, which 
evaluates the HRES according to Eq. (2) [59].

$\operatorname{LPSP}=\sum_{t=1}^{T} \operatorname{LPS}(t) / \sum_{t=1}^{T} E_{\text {load }}(t)$

where $\operatorname{LPS}(t)$ is the supply power loss $(\mathrm{kW})$ when the energy generated by the RES is lower than the load demand. In addition, $E_{\text {load }}(t)$ is the power consumed by the load at hour $\mathrm{t}(\mathrm{kW})$.

Apart from a supply power loss caused by unpredictable weather conditions, the equipment failure of HRES may also cause a shutdown during the operation. Moreover, several events may cause shutdowns resulting in power supply loss. Therefore, a new energy reliability index needs to be suggested for the loss of power supply, indicating shutdown events when the electricity supply is lower than the electricity load. The shutdown events of the PV panels and wind turbines are shown in Tables S3 [60] and S4 [61]. The annual potential downtime of individual equipment caused by each failure event is calculated to estimate the possible shutdown time using Eq. (3):

$T_{P D T}=\sum f_{i} \cdot T_{M D T, i}$,

where $T_{P D T}$ is the potential downtime, $f_{i}$ is the failure rate of each fault event, and $T_{M D T, i}$ is the mean downtime caused by each fault event. Considering that the downtime causes power losses, the new energy reliability can be referred to as the potential loss of power supply probability (PLPSP), described by Eq. (4).

$P L P S P=\left(L P S+T_{P D T} \cdot E_{\text {load }, \text { ave }}\right) / E_{\text {load }}$,

where $E_{\text {load,ave }}$ is the average daily electricity demand, and PLPSP is the potential loss of power supply. 


\section{Mathematical model}

In this section, the optimization problem of the HRES is formulated based on two criteria; which is consequently solved by a mathematical model with the purpose of designing an integrated system with lower capital and operational costs for the HRES, (i.e., solar panels and wind turbines) and lower environmental effects due to the energy supply systems (i.e., solar panels, wind turbines, and conventional electricity grid).

The hourly power supply volume from the HRES and the power consumption by the RO system are obtained by a system component model, as shown in section 2 of the SI. The proposed algorithm considered the future fluctuations using forecasted data as the input parameters to the system component model. Then, it is possible to obtain the unit power supply provided by a single HRES module, and the total power consumption by the amount of water produced by an RO system.

\subsection{Multi-objective function}

Two objective functions are considered to design the HRES, including the economic benefit and environmental effects. The first objective function considers the economic aspects, which are calculated through the total annual cost as shown below in Eq. (5). The total annual cost (TAC) is calculated based on the summation of the total annual cost for the entire HRES with all PV panels and wind turbines.

$T A C=T A C_{P V}+T A C_{W T}$

where $T A C_{P V}$ is the total annual cost of the PV panels, and $T A C_{W T}$ is the total annual cost of the wind turbines. 
Additionally, the second objective function corresponds to an environmental objective calculated according to Eq. (6). The total GHG emissions were calculated from the hybrid power supply system considering the GHG released from the conventional grid as well as from the HRES.

$L C E=L C E_{\text {grid }}+L C E_{P V}+L C E_{W T}$,

where $L C E$ is the lifecycle GHG emissions, and the subscripts grid, $P V$, and $W T$ represent the different emission sources, including the conventional grid, the PV panels, and the wind turbines, respectively.

\subsection{Total annual cost of the first objective}

An economic model of the HRES is implemented to estimate the economic efficiency of the energy supply system. The overall cost of an HRES during its whole life includes the installation, operation, maintenance, and replacement costs $[59,62,63]$. The TAC was determined to express the cost of individual RES on a yearly basis. Eq. (7) shows the TAC for each equipment unity.

$T A C_{m}=A C C_{m}+A O M C_{m}$,

where $A C C$ is the annual capital cost, and $A O M C$ is the annual operating and maintenance cost. The subscript $m$ can represent either the solar panel or wind turbine in such a way that the TAC of the solar panel and wind turbine can both be expressed as in Eq. (7).

Mathematically, the calculations of the $A C C$ and $A O M C$ are presented as follows:

$A C C=C C \times A F$, and

$A O M C=O M C \times A F=f \times C C \times A F$, 
where $C C$ is the capital cost of the equipment of the RES, OMC represents the operating and maintenance costs, which are calculated by multiplying $C C$ with a coefficient $(f)$, referred to as the operation and maintenance coefficient. On the other hand, $L T_{s y s}$ is the lifetime of the overall energy system, and $L T_{m}$ is the lifetime of the RES. To obtain the annual cost of each item, the amortization factor (AF) is multiplied by each item cost, which is calculated by Eq. (10).

$$
A F=\frac{i r \times(1+i r)^{L T_{s y s}}}{(1+i r)^{L T_{s y s}}-1},
$$

where $i r$ is the interest rate. The parameters used in Eq. (5) to (10) are shown in Table 2.

Table 2. Parameters used in the economic model of the HRES. [16]

\begin{tabular}{ccccc}
\hline Subsystems & Parameters & Symbol & Value & Unit \\
\hline PV & Capital cost & $C C_{p v}$ & 380 & $\$ /$ module \\
& Operation and maintenance coefficient & $f_{p v}$ & 0.03 & $\backslash$ \\
\multirow{3}{*}{ Wind turbine } & Lifetime & $L T_{p v}$ & 25 & year \\
& Capital cost & $C C_{w t}$ & 25,000 & $\$ /$ unit \\
& Operation and maintenance coefficient & $f_{w t}$ & 0.027 & $\backslash$ \\
\multirow{3}{*}{ Others } & Lifetime & $L T_{w t}$ & 25 & year \\
& Lifetime of overall system & $L T_{s y s}$ & 25 & year \\
& Interest rate & $i r$ & 0.15 & $\%$ \\
\hline
\end{tabular}

3.3. Lifecycle greenhouse gas emission of the second objective

Environmental impact is a major aspect that should be considered in the optimal design of an HRES. In several studied energy supply systems, the dominant GHG emissions correspond to the electricity supplied from energy grids sourced by conventional power plants (i.e., fossil fuels). For example, the lifecycle GHG emission of a conventional power 
plant in London follows a rate of $0.5484 \mathrm{~kg} \mathrm{CO} / \mathrm{kWh}$ [64]. In this research, the lifecycle GHG emission of a renewable energy system was considered as well.

During the operational period, the PV panel and wind turbine seemed to provide no GHG emissions because they are widely considered to be green energy sources. However, during the lifetime of the RES, certain activities such as the construction process are responsible for major GHG emissions [65]. The lifecycle GHG emissions for solar panels and wind turbine are shown in Tables 3 and 4, respectively.

Table 3. Lifecycle GHG emissions of the solar power generation system [62].

\begin{tabular}{ccc}
\hline Components & GHG emissions $\left(\mathrm{g}-\mathrm{CO}_{2} / \mathrm{kWh}\right)$ & Share $(\%)$ \\
\hline Construction & 41.1 & 76.9 \\
PV panel & 28.3 & 53 \\
Support & 9.8 & 18.3 \\
Others & 3 & 5.6 \\
Operation & 12.3 & 23.1 \\
Total & 53.4 & 100 \\
\hline
\end{tabular}

Table 4. Lifecycle GHG emissions of the wind power generation system [62].

\begin{tabular}{ccc}
\hline Components & GHG emissions $\left(\mathrm{g}-\mathrm{CO}_{2} / \mathrm{kWh}\right)$ & Share $(\%)$ \\
\hline Construction & 21.2 & 71.9 \\
Foundations & 7.4 & 25.1 \\
Blades & 1.4 & 4.8 \\
Nacelle & 5.9 & 20 \\
Tower & 3.4 & 11.7 \\
Turbine & 3.1 & 10.3 \\
Operation & 8.3 & 28.1 \\
\hline
\end{tabular}




\subsection{Constraints of electric power transmission}

To find an optimal solution, several constraints need to be defined and satisfied. A block diagram of electricity transport routes is shown in Fig. 4. There are three electricity sources, including AC electricity from the wind turbine, DC electricity from the PV panel, and electricity from a conventional grid to the RO system, which correspond to the standalone electricity demand. The arrows indicate the direction of power transmission; moreover, the symbol $\mathrm{x}$ on the arrows denotes the specific amount of electricity transmission. The junction point $\mathrm{Y}$ is a binary variable with a value of 1 or 0 , which can be considered as a 'switch.' If the 'switch' is turned on (i.e., $\mathrm{Y}$ is equal to 1), this means that power transmission occurs; otherwise, there is no electricity passing through this route. The constraints consider the following:

1) Source-demand electricity balance. The amount of electricity generated by PV panels and wind turbines can be delivered to the RO system through routes $x_{3}$ and $x_{6}$, and the amount of electricity stored in the BSS can also supply power to the RO system through route $x_{7}$. In the meantime, the conventional power plant provides electricity through route $x_{8}$ when HRES cannot meet the demand. Therefore, the power supplied through $x_{3}, x_{6}, x_{7}$, and $x_{8}$ should be equal to $x_{9}$. Considering the power losses in the transmission process, the source-demand balance equation at each time interval can be expressed as shown in Eq. (11).

$$
x_{9, i}=\lambda \cdot x_{3, i}+x_{6, i}+\lambda \cdot \delta \cdot x_{7, i}+x_{8, i},
$$


where $\lambda$ denotes the electricity converter efficiency from DC to AC electricity (or AC to DC electricity), which is assumed to be $95 \%$. Furthermore, $\delta$ is the battery efficiency when a charge or discharge occurs, which is assumed to be $90 \%[8,66]$. The subscript $i$ denotes the time interval.

2) A battery balance shows that the electricity stored in the battery should satisfy the following equation:

$B s_{i}=(1-\alpha) \times B s_{i-1}+x_{4, i}+\delta \cdot x_{5, i}-x_{7, i}$,

where $\alpha$ expresses the battery self-discharge rate with a value of $0.004 \% / \mathrm{h}$ [66].

Therefore, the battery electricity at time interval $i$ is equal to the amount stored in the previous time interval (i-1) plus the charging electricity from the PV panel and the wind turbine minus the amount discharged to an RO system.

3) A disjunction program is defined because a serial constraint should be satisfied in the junction point:

$$
\begin{aligned}
& {\left[\begin{array}{c}
Y_{1, i} \\
x_{1, i} \geq x_{3, i}+x_{4, i}
\end{array}\right] \vee\left[\begin{array}{c}
\neg Y_{1, i} \\
x_{3, i}=0 \& x_{4, i}=0
\end{array}\right],} \\
& {\left[\begin{array}{c}
Y_{2, i} \\
x_{2, i} \geq x_{5, i}+x_{6, i}
\end{array}\right] \vee\left[\begin{array}{c}
\neg Y_{2, i} \\
x_{5, i}=0 \& x_{6, i}=0
\end{array}\right],} \\
& {\left[\begin{array}{c}
Y_{3, i} \\
B s_{i} \geq(1-\alpha) \times B s_{i-1}+x_{4, i}+\delta \cdot x_{5, i}
\end{array}\right] \vee\left[\begin{array}{c}
\neg Y_{3, i} \\
B s_{i} \geq(1-\alpha) \times B s_{i-1}-x_{7, i}
\end{array}\right],} \\
& {\left[\begin{array}{c}
Y_{4, i} \\
x_{8, i} \leq x_{9, i}
\end{array}\right] \vee\left[\begin{array}{c}
\neg Y_{4, i} \\
x_{8, i}=0
\end{array}\right]}
\end{aligned}
$$




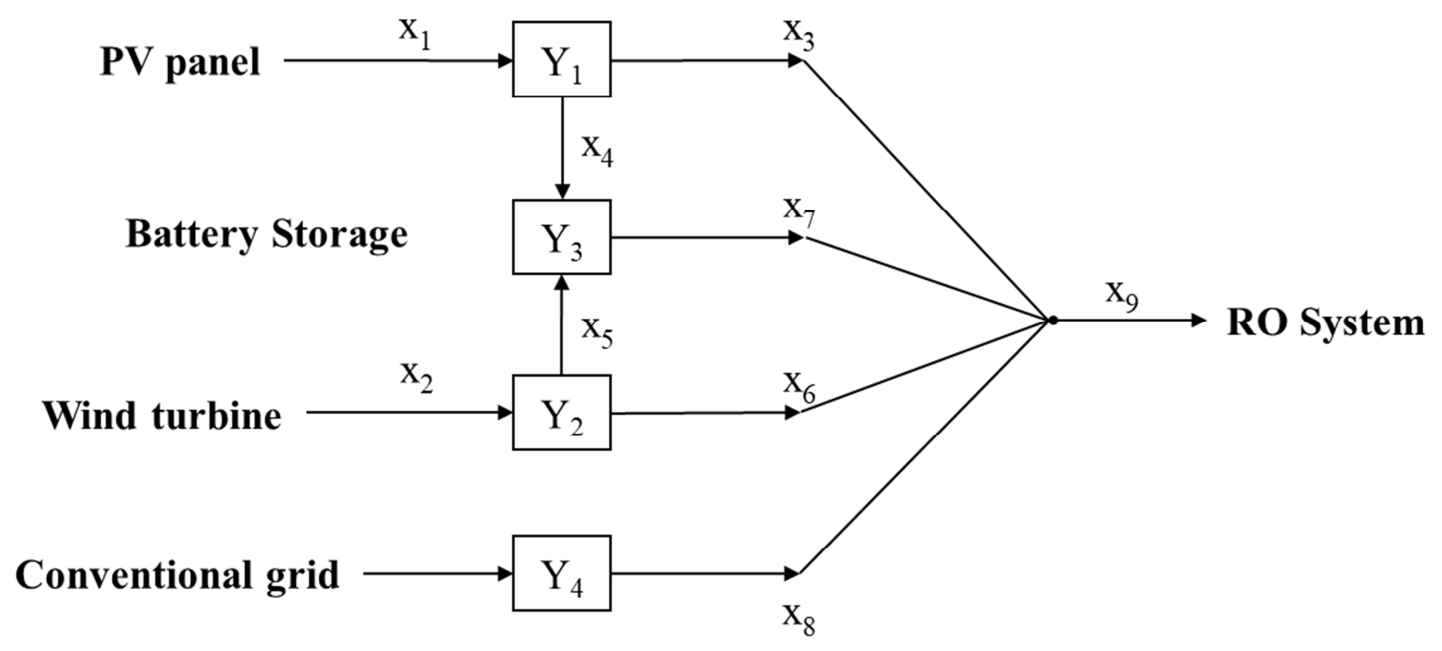

Fig. 4. Electricity transport network of the HRES-RO system.

\section{Results and discussion}

The proposed framework was applied to analyze several aspects of the performance for the integration of an HRES-RO system in the case of forecasting the source availability and dynamic freshwater demand, with the London Home Office as a case study. The aim of the framework includes the assessment of this system considering future uncertainties in the HRES-RO reliability, total annual costs, and environmental impact. Moreover, local datasets were utilized, and the results are detailed in the following sections.

\subsection{Demand load and RE sources predictions}

The predictive algorithm consists of a moving window using an RNN structure with the incorporation of memory cells (i.e., LSTM, GRU). Then, the structure that presents the lowest value of RMSE is selected as the most suitable prediction technique. It should be noted that the accuracy of the forecasting model is deteriorated as the window size is enlarged due to the consequent lack of information, and errors accumulation during the forecasting 
process. However, it is necessary to obtain long-term forecasting sequences of the renewable sources' availability for designing, planning, and scheduling an RES $[21,22,67]$. For these reasons, the RNN structures coupled with memory cells are suitable for this task since they can capture several intrinsic features of the data, including dynamic disturbances and patterns, including seasonal changes for the meteorological variables, and the behavior of the consumers when forecasting the freshwater demand [54,68]. Thus, capturing future patterns results in an adequate indicator to anticipate the supply chain of freshwater production.

Table 5 shows the results of the forecasting structures compared using the RMSE metric. The GRU structure outperforms the LSTM as it provides lower values of RMSE. Therefore, this structure is selected for determining the necessary variables. On the other hand, the LSTM outperforms the GRU structure on the wind speed prediction. Then, after selecting the most suitable predictive model for each target, an iterative algorithm allows forecasting for the whole year 2018, as shown in Fig. 5. Here, the trend of each variable is marked by following its monthly average; moreover, it should be noted that the ambient temperature (Fig. 5(b)) and solar radiation (Fig. 5(c)) show a well-defined pattern according to the different seasons, and daily conditions. On the other hand, water consumption (Fig. 5(a)), and the wind speed (Fig. 5(d)) showed a sparse trend; this may occur due to the erratic behavior of the wind speed which is not always related to seasonal or daily conditions. Moreover, water consumption is related to the behavior of the consumption which may vary from household to household. The efforts from the moving window predictive model were to capture localized patterns within the window that may not be captured from a low time resolution learning process. The assessment of the HRES-RO performance is then conducted 
using the forecasted data for the year 2018 .

Table 5. RMSE for the predictive models with different RNN structures with memory cells.

\begin{tabular}{ccc}
\hline Target & Structure & RMSE \\
\hline \multirow{2}{*}{ Freshwater demand } & LSTM & 9.3303 \\
& GRU & $\mathbf{9 . 1 2 4 8}$ \\
\cline { 2 - 3 } Ambient temperature & LSTM & 0.9565 \\
\cline { 2 - 3 } Solar radiation & GRU & $\mathbf{0 . 9 3 9 7}$ \\
\cline { 2 - 3 } & LSTM & 190.532 \\
Wind speed & GRU & $\mathbf{1 8 7 . 0 6 2 7}$ \\
\cline { 2 - 3 } & LSTM & $\mathbf{1 . 5 9 0 4}$ \\
\hline
\end{tabular}

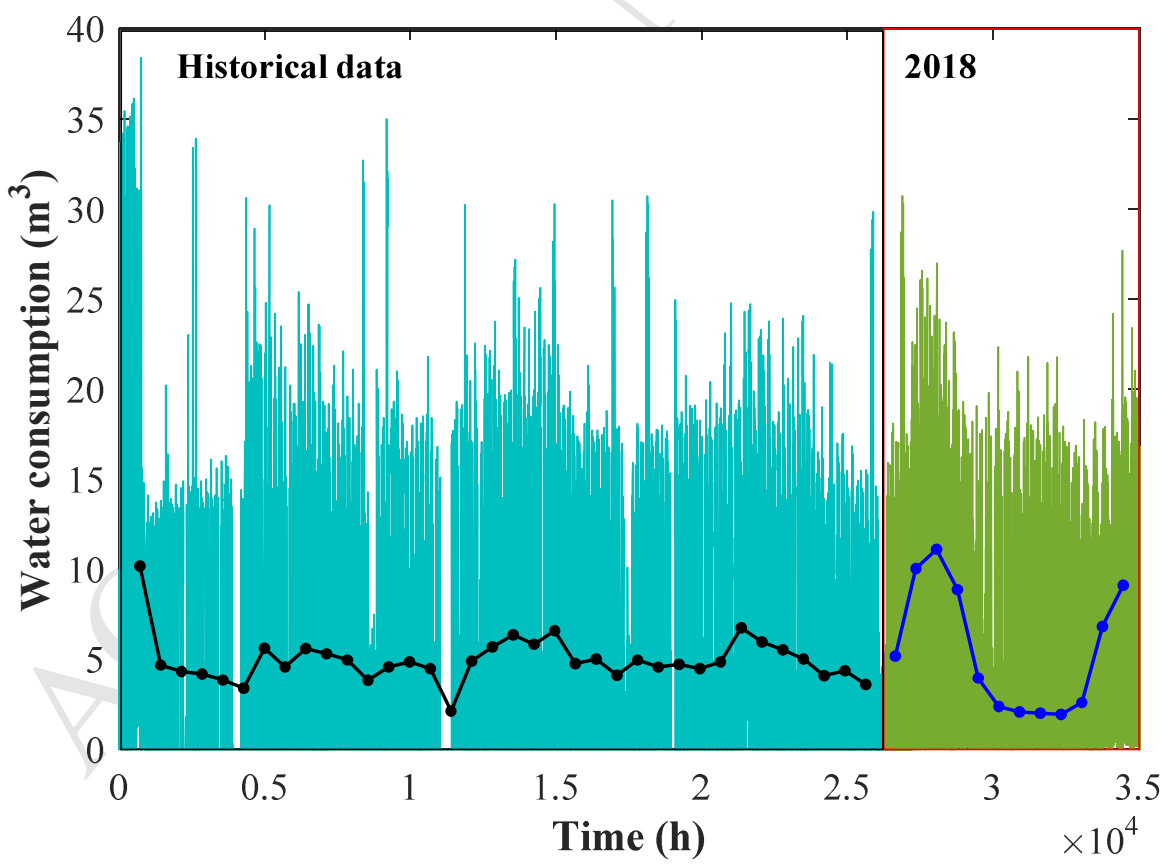

(a) 


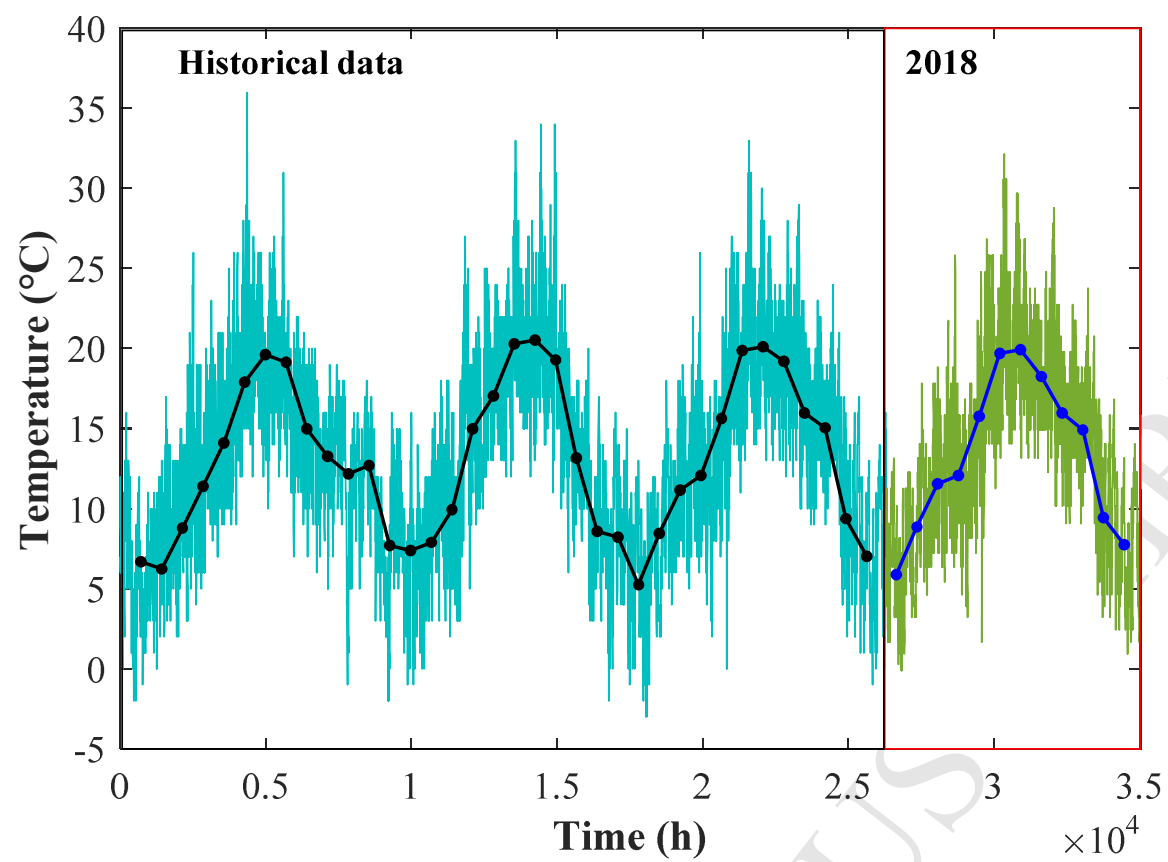

(b)

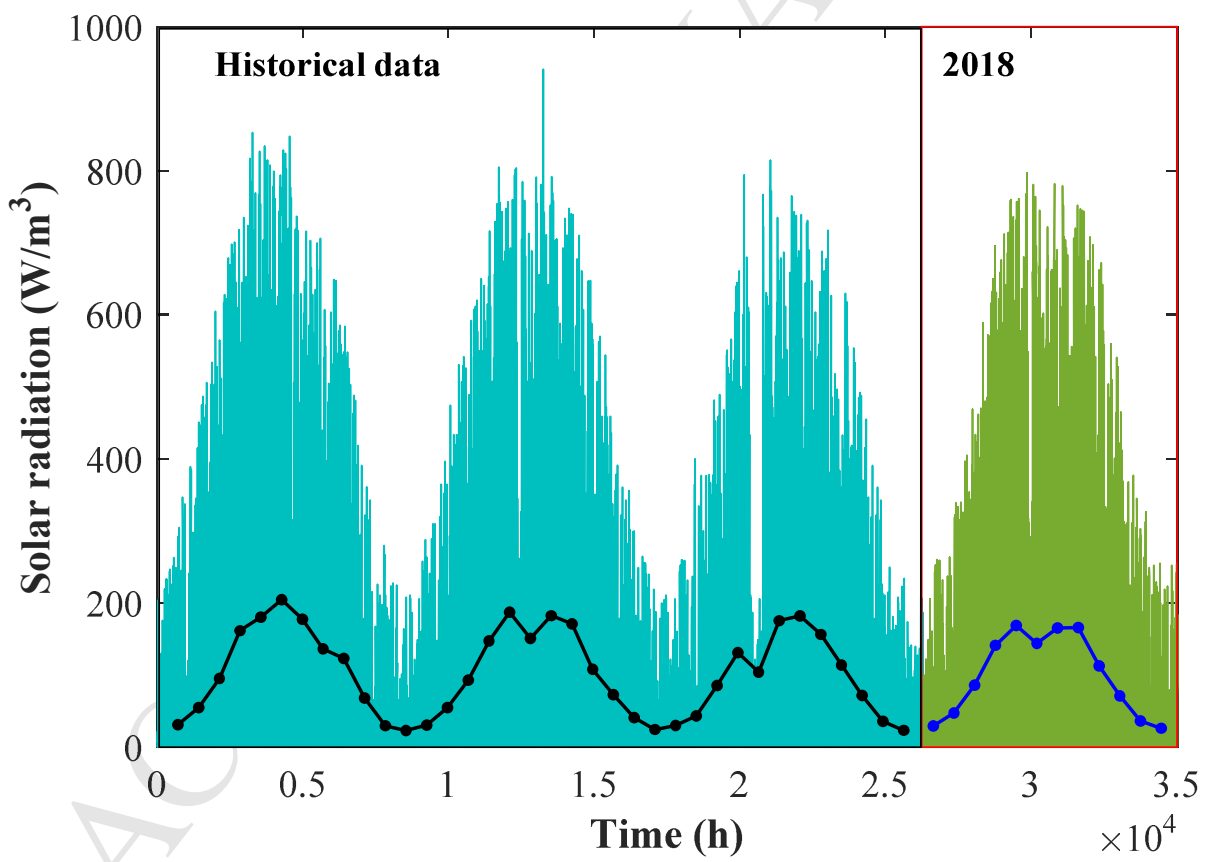

(c) 


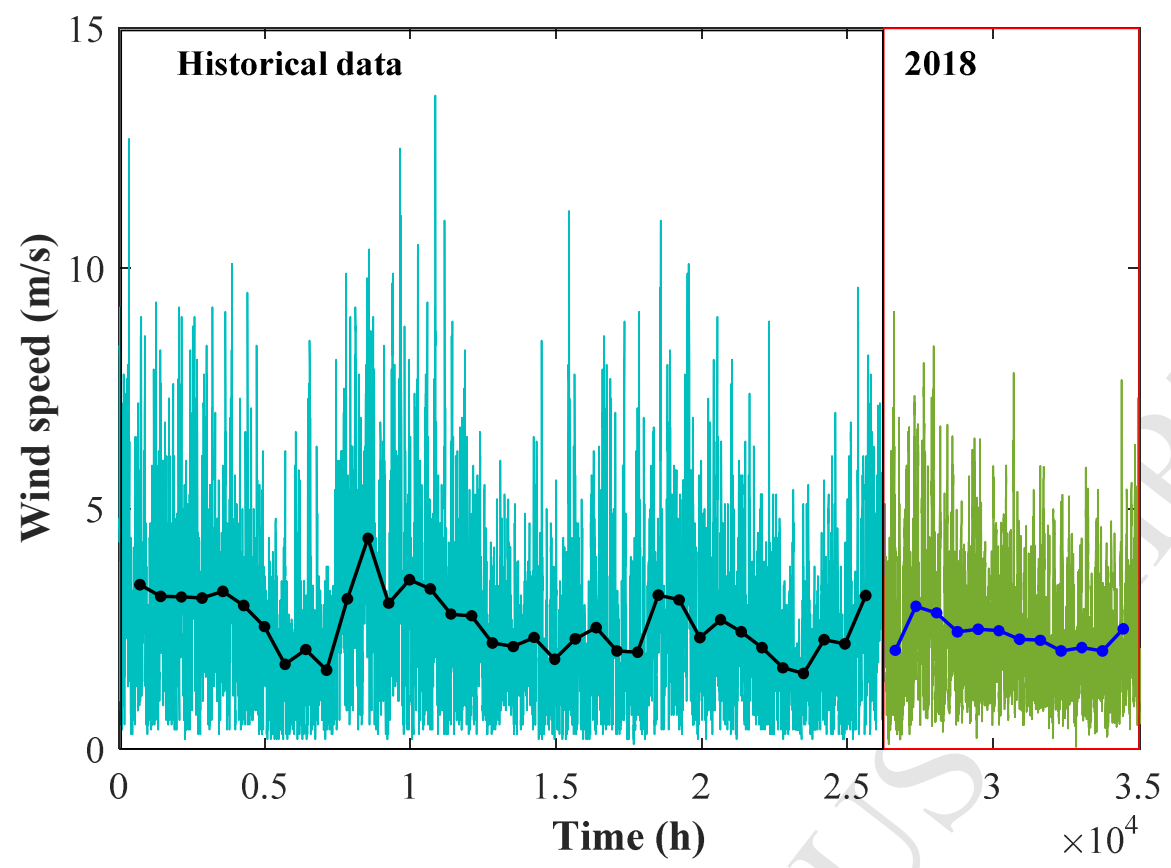

(d)

Fig. 5. Forecasted data for the year 2018 of (a) freshwater demand, (b) ambient temperature, (c) solar radiation, and (d) wind speed.

\subsection{Optimal design of the HRES}

A mathematical model was developed to design the HRES considering two major aspects, including environmental and economic effects. Three scenarios were specified for the base and proposed procedures by using different RESs defined as follows: 1) The first scenario considers the combination of PV panels and wind turbines (i.e., the complete HRES). 2) The second scenario uses only the PV panels for energy supply. 3) Finally, the wind turbines (WT) represent the only energy source in the third scenario. Furthermore, a BSS is considered in all three scenarios, assuming a capacity of $1,000 \mathrm{~kW}$. This means that the stored amount of electricity at each time interval (hourly resolution) cannot exceed the previously mentioned capacity value. In the case study of the London Home Office, the optimal size of RES is 
determined to efficiently satisfy the electricity demand from the freshwater production via RO desalination system. The hourly variation of supply and demand electricity is calculated based on the system components model (shown in SI section 2), considering the real variation of weather conditions and water consumption; additionally, the generated electricity from the individual RE unit (PV panel and wind turbine) with their corresponding demand electricity from RO is implemented into the multi-objective EMP model to obtain the optimal size of RE components.

The Pareto front of the two introduced optimization procedures case studies, and multi-objective optimizations of each case with three scenarios are shown in Fig. 6. The designed HRES-RO system with maximum GHG emissions is shown in the top left corner indicating that the electricity needed for the RO was provided completely by the conventional grid. The point at the lower right corner indicates more RE was considered in the electricity supply system with a larger TAC but lower GHG emission. Considering the purpose of this study, the optimal size needs to be defined as the system with a minimum of both TAC and GHG emissions. Therefore, to contrast the performance of the RES in each case, the optimal points were selected with an equal GHG emissions yearly rate $\left(4 \times 10^{4} \mathrm{~g}-\mathrm{CO}_{2-\mathrm{eq}} / \mathrm{year}\right)$; then, it is expected that the RES yields low values for the TAC. In the trade-off curve for each case, the optimal points selected from the comparison among the introduced HRES-RO systems are represented by a red star in Fig. 6.

The optimal points had similar GHG emissions, while the TAC showed behavioral variations due to the different datasets utilized in the proposed cases (forecasting data), and base cases (historical data). Following, the TAC ranged from $2 \times 10^{4}$ to $5.5 \times 10^{4}$ US $\$$ for the 
selected points. The detailed information of the optimal points of the HRESs for each scenario is shown in Table 6. The power supply EMP algorithm was implemented with the optimal size of HRES to improve the efficiency of the power supply chain and identify optimal characteristics, as shown in Table 6. Comparing the proposed cases with the base cases, the TAC of the HRES for the proposed cases were higher than the TAC of the base cases.

For proposed case $1(\mathrm{P}-1)$, the optimal size of the complete HRES for the solar panels and wind turbines were 111 and 5 units, respectively. The corresponding TAC was 38,294 US\$, and the RES can supply $45.76 \%$ of the power needed by the RO desalination system. In the case of P-2, the size of the RES provided by the PV panels considered the installation of 395 PV panels. The corresponding TAC was 55,447 US\$, which resulted in the highest of these six cases; additionally, 67,798 kWh/year outsourced electricity was needed in this system. For case P-3, 11 wind turbines were needed to generate the necessary power for the RO system; additionally, the TAC was 49,967 US\$, and the power supplied by the wind turbines can satisfy $44.63 \%$ of the total electricity demand from the RO system. Scenario one of base case (B-1) presented the lowest TAC (21,808 \$) amount in the case studies with 123 PV panels, and a single wind turbine. However, case B-1 represents a relatively high value of outsourced electricity, which means that the designed HRES cannot meet the demand in most of the analyzed time interval. Therefore, considering the economic cost and the environmental effects are not sufficient tools for the design of an optimal RES. Additionally, the energy reliability should be introduced as an indicator for optimizing the RES and determining the future behavior of the system. 


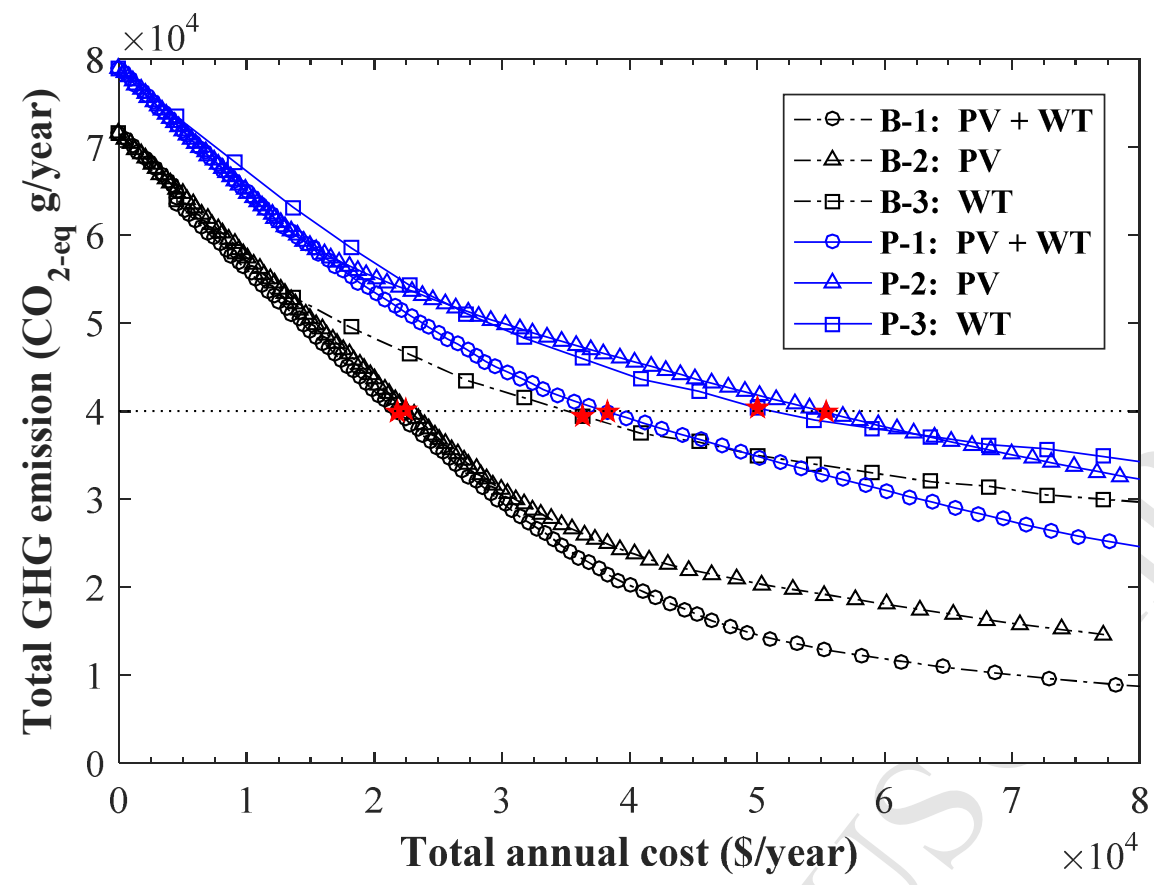

Fig. 6. Multi-objective optimization results of three RES scenarios, namely, PV-WT, PV, and WT, using the basic analysis procedure $(\mathrm{B})$ and proposed analysis procedure $(\mathrm{P})$ based on TAC and total GHG emissions.

Table 6. The optimal characteristics of the RES of each case.

\begin{tabular}{lcccccc}
\hline & P-1 & P-2 & P-3 & B-1 & B-2 & B-3 \\
\hline Number of PV & 111 & 395 & 0 & 123 & 160 & 0 \\
Number of WT & 5 & 0 & 11 & 1 & 0 & 8 \\
Battery size (kWh) & 1,000 & 1,000 & 1,000 & 1,000 & 1,000 & 1,000 \\
$\begin{array}{l}\text { Electricity from power } \\
\text { grid (kWh) }\end{array}$ & 65,914 & 67,498 & 64,285 & 92,287 & 95,102 & 75,304 \\
TAC (\$/year) & 38,294 & 55,447 & 49,967 & 21,808 & 22,459 & 36,340 \\
\hline
\end{tabular}

Figure 7 depicts the monthly electricity supply and demand for the HRES-RO system in the case studies. The electricity demand for each scenario is equal since they were computed based on the forecasted water demand data in the year 2018. Moreover, the electricity supply 
for each scenario was calculated based on the optimal number of modules with the forecasted weather conditions in the year 2018. As illustrated from the forecasting results (Fig. 5), both supply and demand electricity have well-defined periodical variation due to the seasonal change of the weather conditions.

The supplied electricity from the PV system is high and low during summer and winter seasons, respectively. The electricity demand from the wind system reaches the highest peak in February and shows a low level from September to November. The electricity demand estimated from water consumption is higher during colder seasons (from January to April and from November to December), and lower during warmer seasons (from May to October). The electricity supply and demand of three proposed cases based on the forecasting model are shown in Figs. 7(a-c) Considering HRES as electricity supply (shown in Fig. 7(a)), the demand for electricity is relatively higher than the supplied electricity during colder seasons. Meanwhile, the total supply of electricity can meet the demand for warmer seasons. The exceeding electricity generated during warmer seasons by the HRES can be stored in the BSS, to be subsequently discharged when the supply cannot meet the demand (such as November and December). In the P-2 case (as shown in Fig. 7(b)), solar energy as the only electricity supply source can meet the electricity demand of RO system with a large electricity surplus during warmer seasons; however, a large gap between supply and demand electricity exists in colder seasons. In the P-3 case (as shown in Fig. 7(c)), the supply electricity from wind energy can satisfy the demand electricity in most of the months excepting April, November, and December. On the other hand, the supplied electricity calculated for the base cases (shown in Figs. 7(d-f)) was lower than the demand in most of the analyzed time intervals due 
to the inappropriate size of the RES.

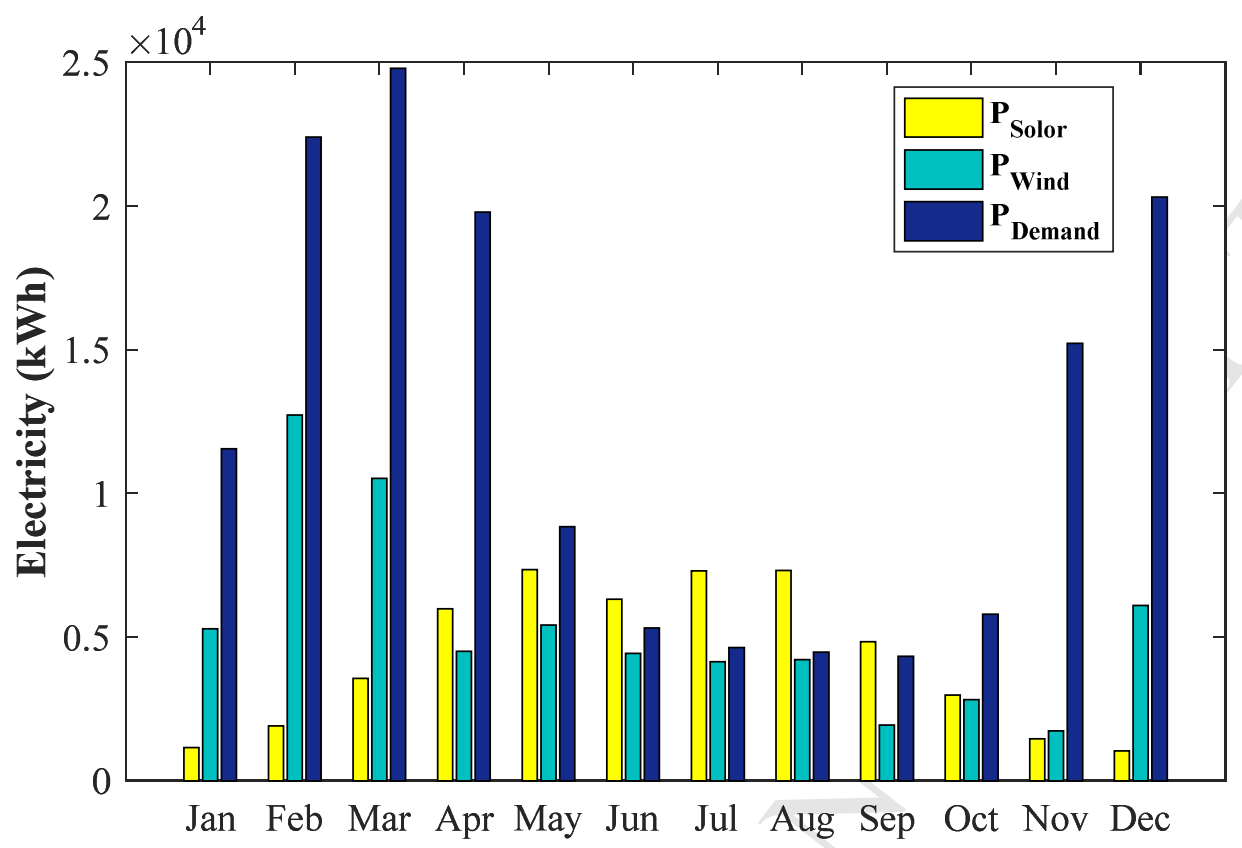

(a)

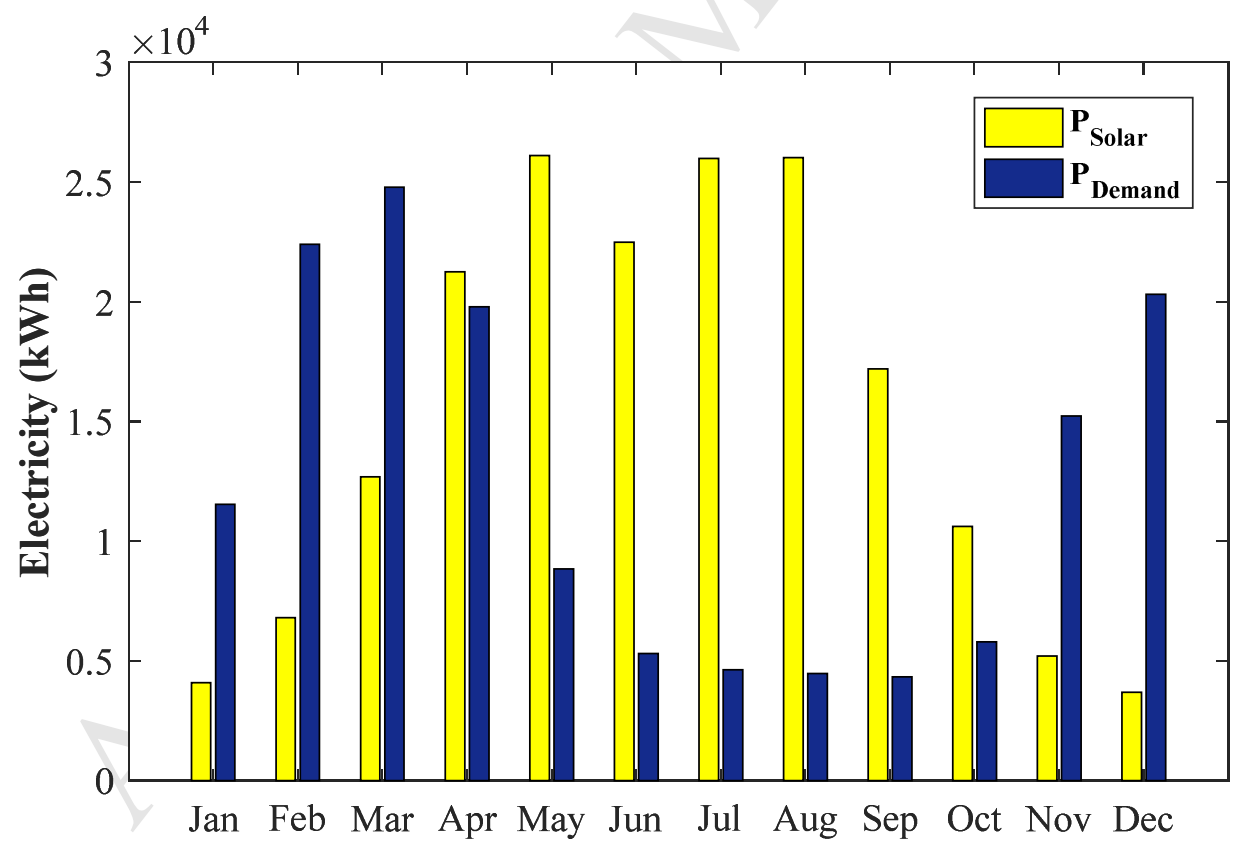

(b) 


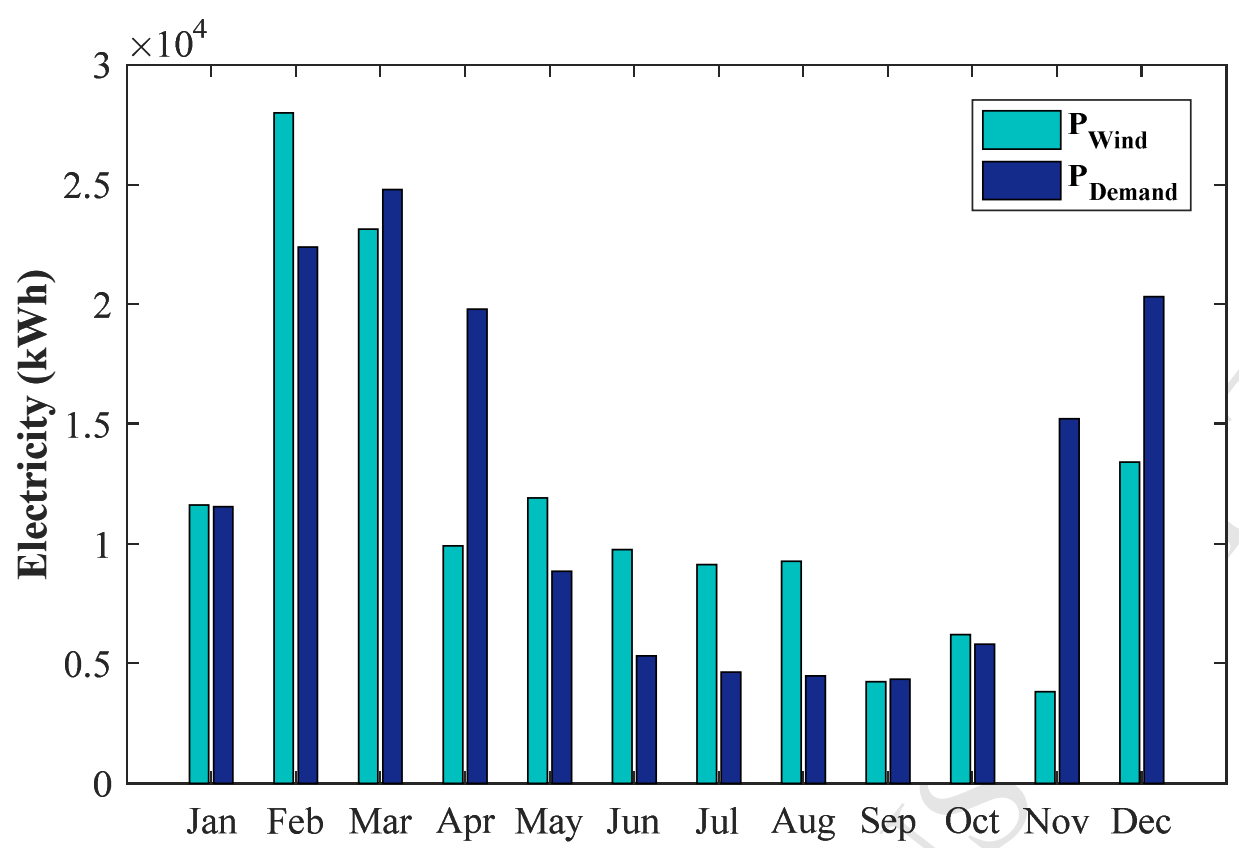

(c)

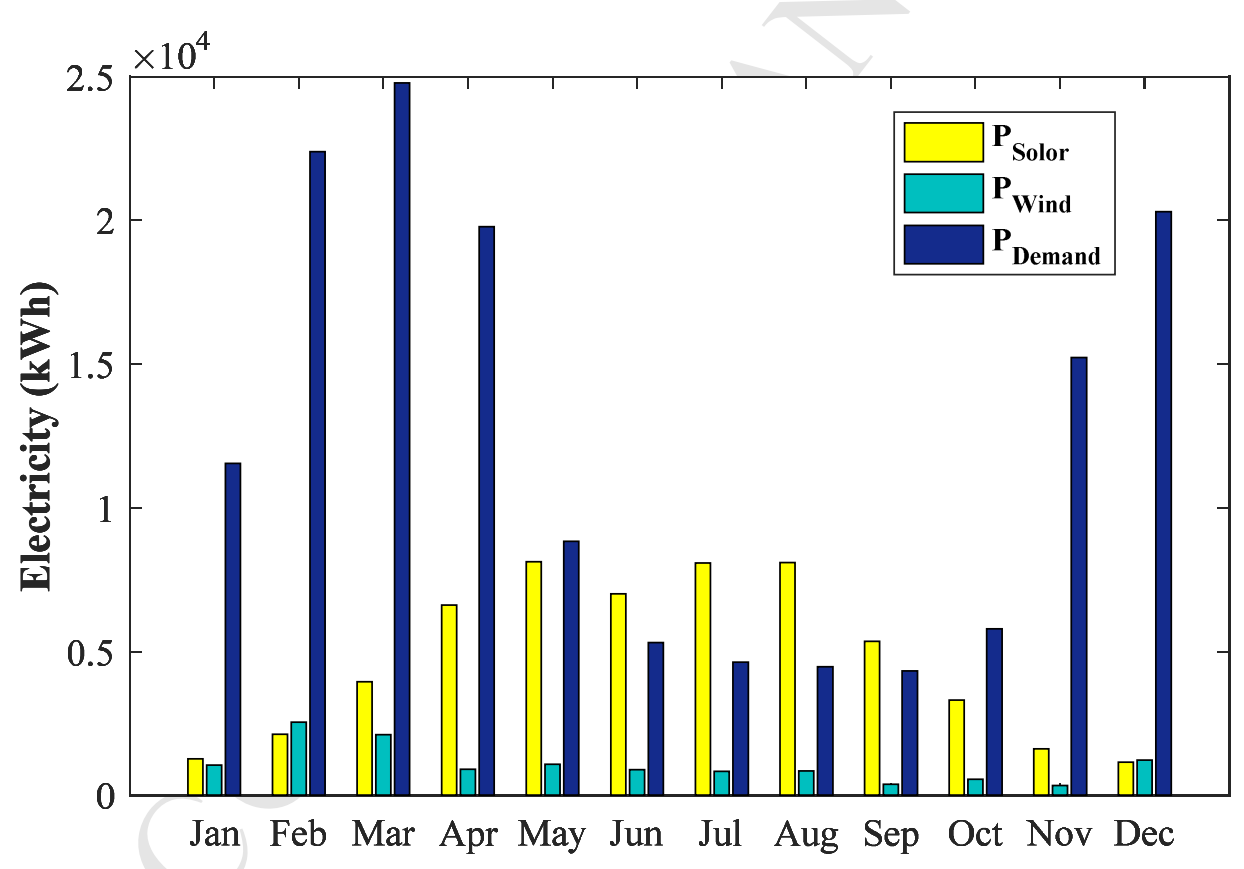

(d) 


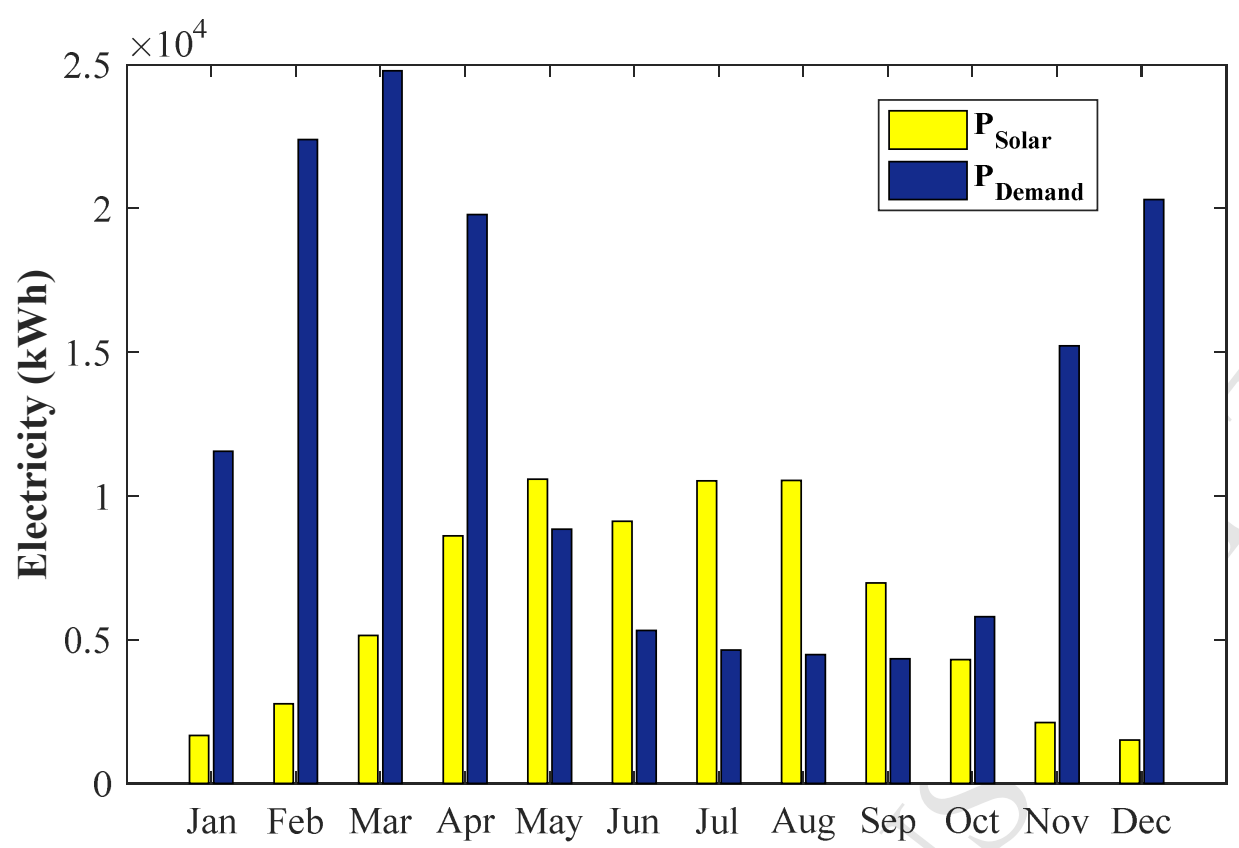

(e)

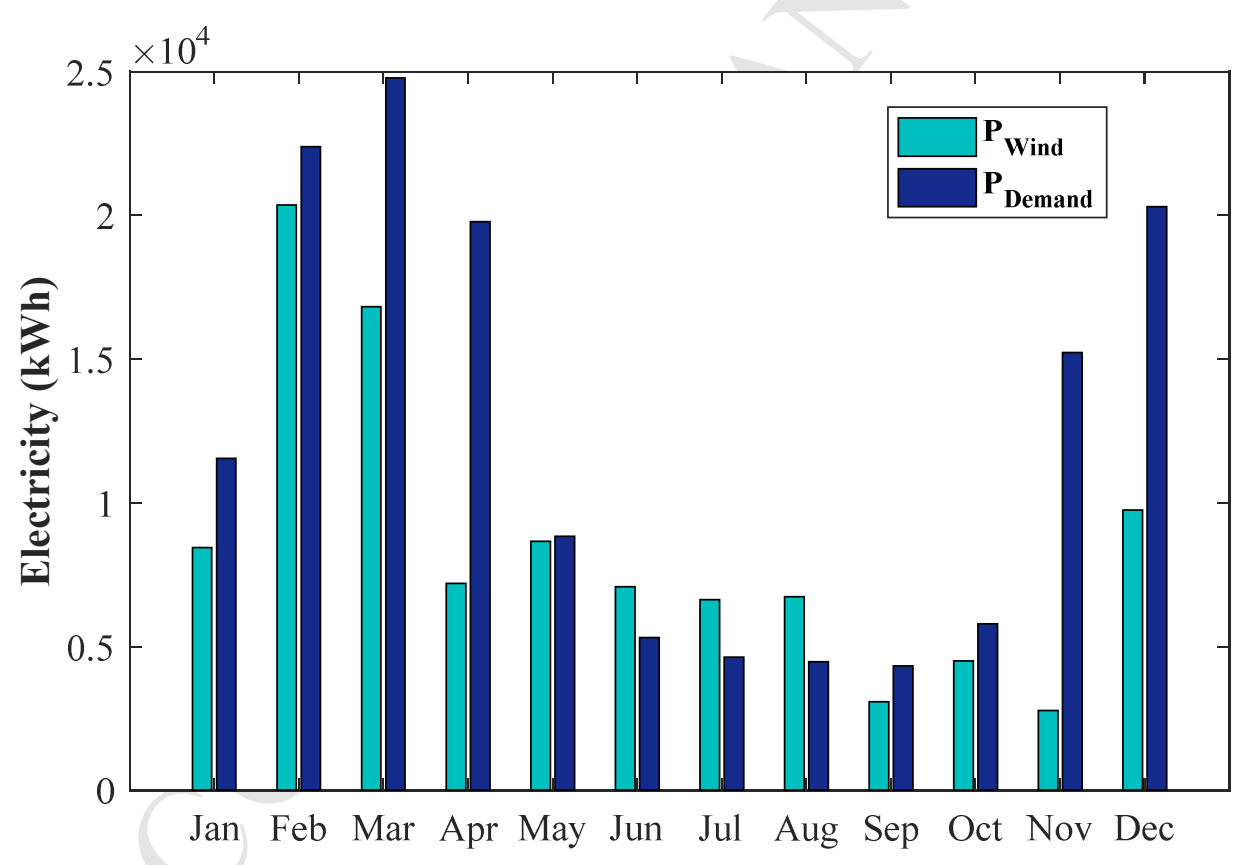

(f)

Fig. 7. Total sources and demand electricity in each month for each scenario. (a) Case P-1, (b) case P-2, (c) case P-3, (d) case B-1, (e) case B-2, and (f) case B-3.

Considering that the maximum battery capacity is a fixed value, the BSS in the 
HRES-RO system mainly depends on the amount of electricity generated by the HRES, and the amount demanded from the RO system. In Fig. 8, the left-hand plot shows the hourly stored electricity in the battery for the six predefined scenarios, and the right-hand figures show a comparison of the freshwater demand and the freshwater produced in the HRES-RO; Figs. 8(a-c) illustrate the results for the proposed cases. In the case of P-1 (as shown in Fig. 8(a)), the BSS is frequently used in the HRES-RO system with a relatively large value of stored electricity. It can be clearly observed that the stored electricity in the battery from May to September (around 3,000 to 7,000 h) is higher than the other months as shown in the left-side figure. On the other hand, the water supply from the designed system can meet the water demand in the same period, as shown in the right-hand plot, in which the light blue line can cover the dark blue line. This phenomenon occurred because the intensity of solar radiation in summer periods is higher than in winter periods, which results in abundant electricity generated by the PV panel, satisfying the demand by storing energy in the battery.

In the case of P-2 (Fig. 8(b)), the stored electricity in the battery reached the highest value at the end of September (about $7000 \mathrm{~h}$ ). Contrary to the case P-1 with a larger amount of electricity stored in the battery during warmer seasons; case P-2 shows a lower value of stored electricity in the battery in this same period. Meanwhile, the water produced by the RO system satisfied the dynamic water load from the consumer in the period of May to September (from 3000 to 7000 h), which indicates that the PV system coupled with a BSS can supply enough power to the RO system. In this study, a great portion of water usage happens during the day time which has a similar pattern with solar energy on a daily basis. Therefore, there is no need to store much capacity in the battery during the warmer periods. 
However, higher water demand is required during colder seasons (from 0 to $2000 \mathrm{~h}$, and from 7000 to 8760 h). The electricity generated by the PV panel is not sufficient to supply the RO system demand. Consequently, a large amount of electricity must be stored in the battery in advance; then, a portion of power harvested by the PV panel is stored in the battery system when of the RO system requires a lower amount of energy than the PV supply.

In case P-3 (Fig. 8(c)), the full-charging battery $(1,000 \mathrm{kWh})$ frequency is larger than the other proposed cases, which reached the maximum value accounting 17 times during the whole operation year. The above phenomenon happens due to the dispersive electricity generated by wind turbines during the year. Clearly, the power generated by the wind turbine could rise to a high level suddenly and may plunge to an extremely low level at the next time interval due to changes in the intrinsic speed, and the nondirectional properties of the wind. Therefore, the battery system should store much more electricity for future predicted demand.

Figs. 8(d-f) illustrate the base case studies with the optimal HRES size determined without a forecasting procedure. Similar to the results of the proposed cases, the freshwater production of cases B-1 and B-2 can meet the water load from May to September (from around 3,000 to 7,000 h). Over a whole year of operation, the balance between water supply and demand showed large gaps with mean values of $3.51 \mathrm{~m}^{3} / \mathrm{h}, 3.62 \mathrm{~m}^{3} / \mathrm{h}$ and $2.87 \mathrm{~m}^{3} / \mathrm{h}$ for cases B-1, B-2, and B-3, respectively; which are greater than the proposed cases. The larger shortage of freshwater production by the RES-RO system in the base cases is caused by inaccurate estimation of the future supply generation and demand consumption. 

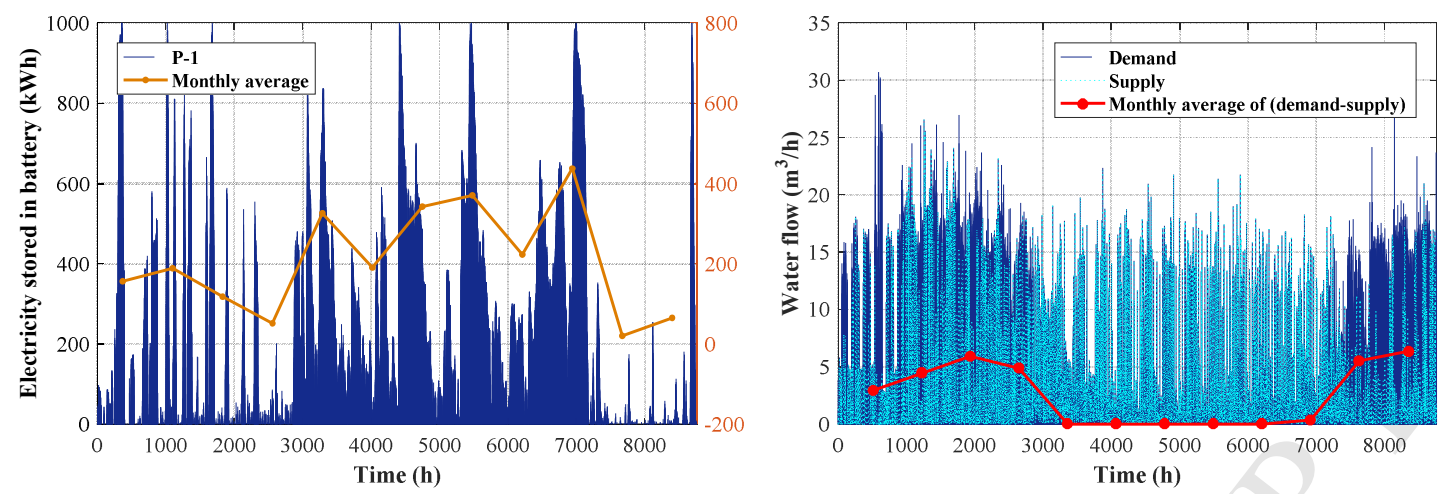

(a)
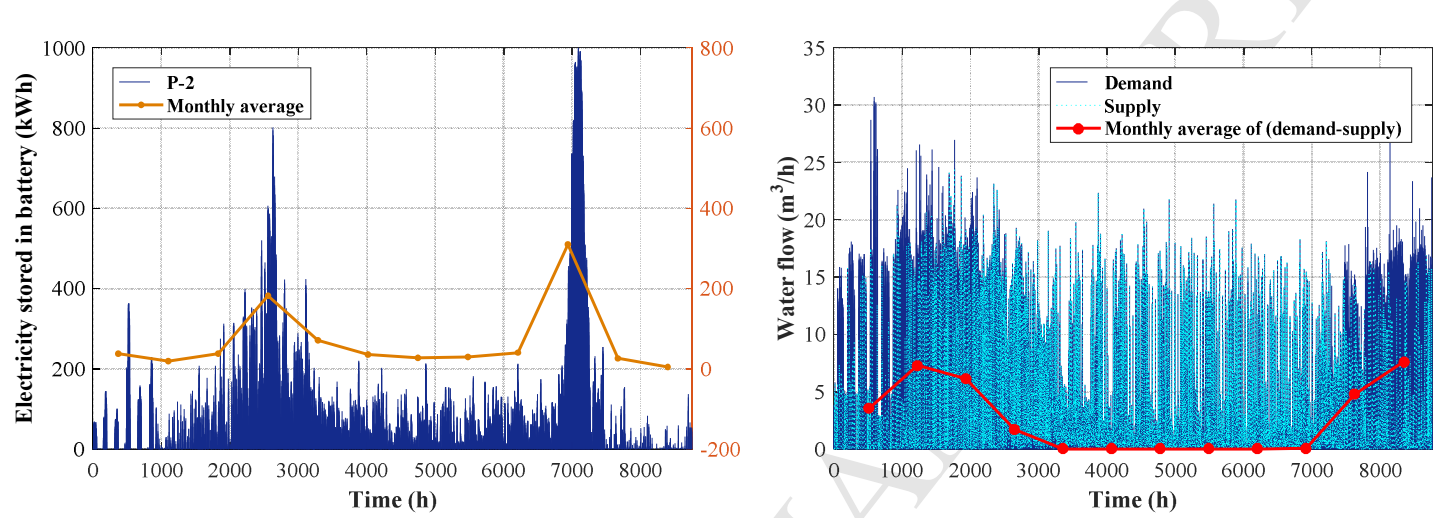

(b)
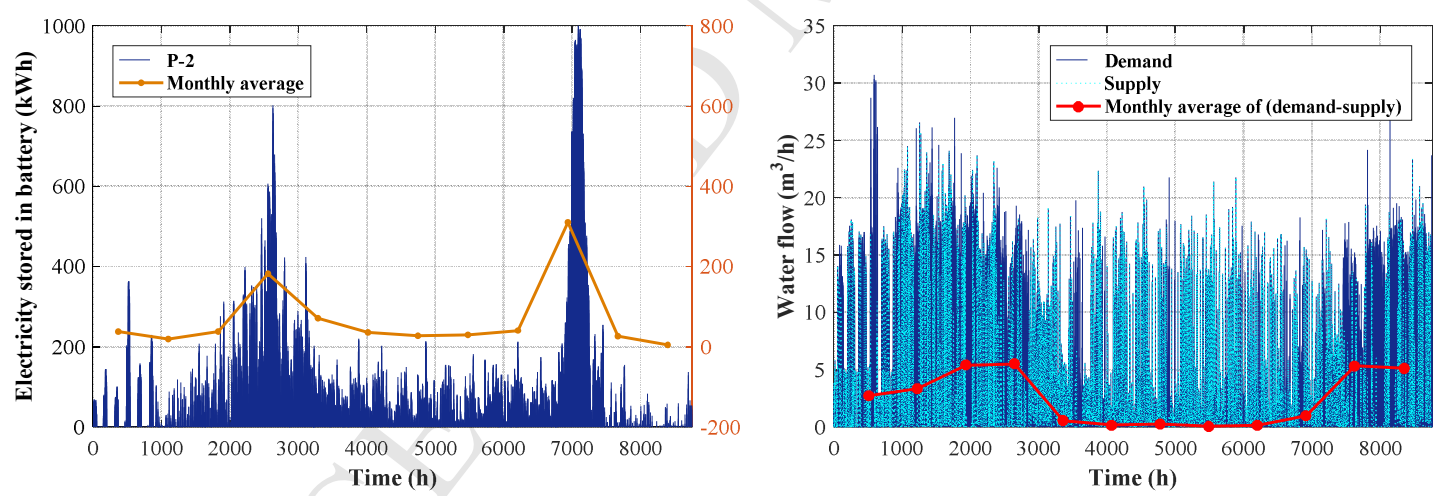

(c)
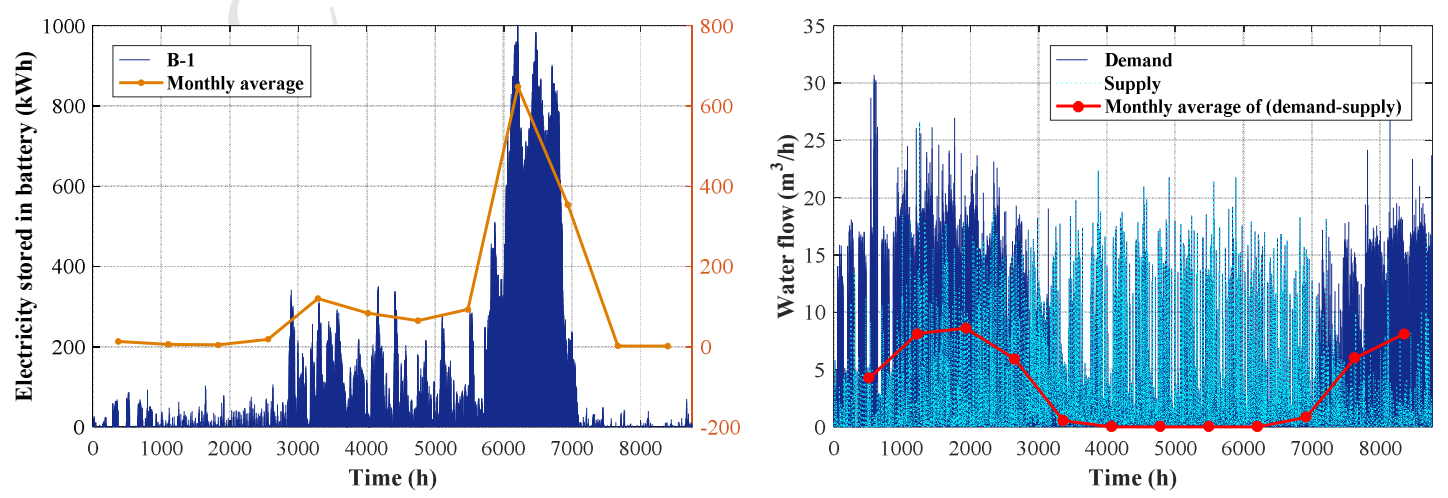

(d) 

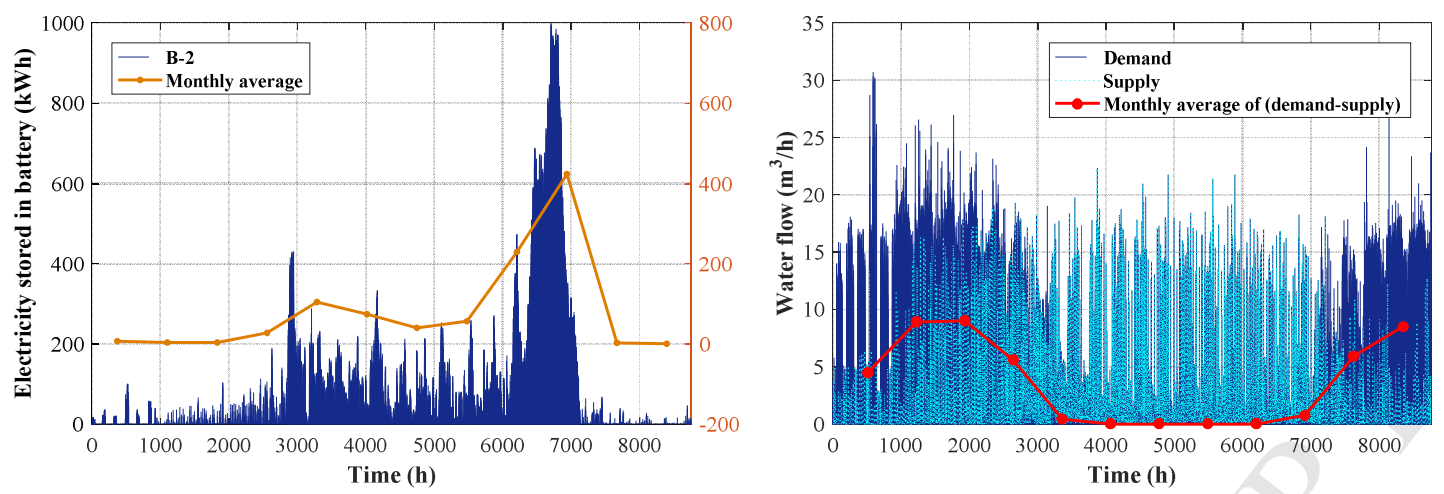

(e)
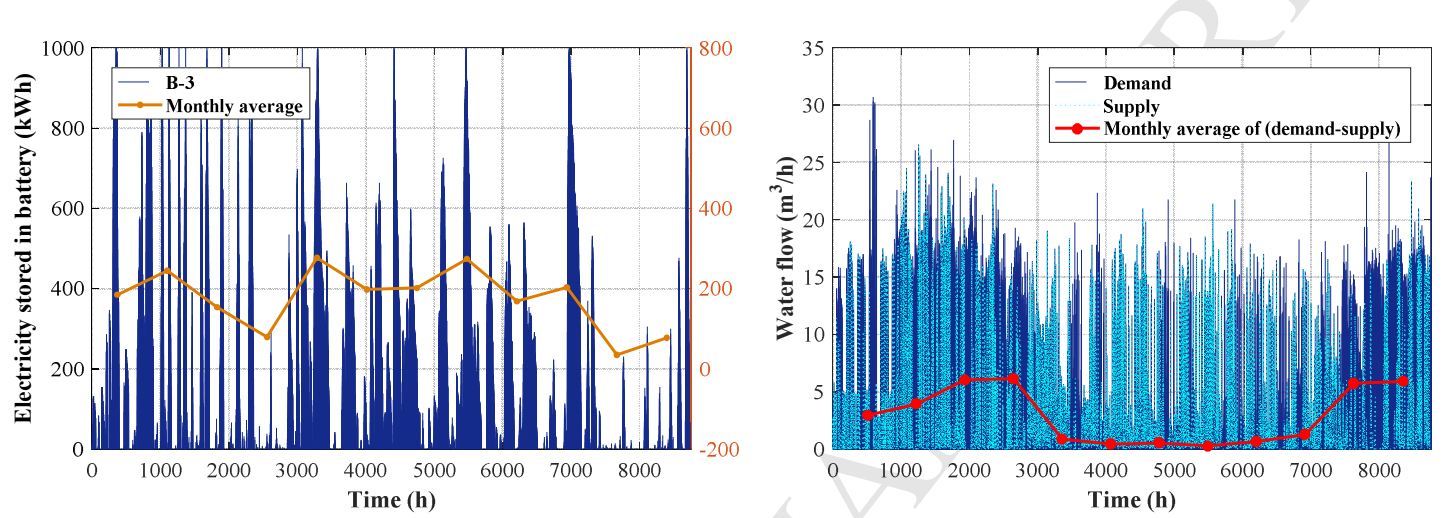

(f)

Fig. 8. The electricity stored in battery (left plot) and water flow (right plot) for (a) case P-1, (b) case P-2, (c) case P-3, (d) case B-1, (e) case B-2, and (f) case B-3.

\subsection{Energy reliability}

The reliability of the HRES was estimated using the LPSP, which is a value between 0 and 1. A value of 0 means that no loss of power exists in the HRES-RO system, which indicates that the HRES system can satisfy the power demand for an RO system, while a value of 1 means that the HRES is not able to satisfy any load. During the whole year operation, the LPSP was obtained by the ratio of the total supply power loss and total power demand. Over this time interval, the LPSP values of the proposed case studies were 0.4576, 0.4707, and 0.4463 , for cases P-1, P-2, and P-3, respectively. In terms of base case studies, 
the LPSP was higher than the proposed cases with values of $0.6407,0.6602$, and 0.5228 for scenarios B-1, B-2, and B-3, respectively. Noticeably, the optimal size of the HRES in base cases did not fully consider the future supply-chain changes, which led to power deficits.

The daily LPSP was calculated for six cases; following, the distribution of the daily LPSP is shown as a histogram in Fig. 9. In all six cases, the LPSP domain belongs to the interval $[0,0.1)$, which indicates that the HRES can satisfy the daily electricity load to a large extent in most of the days within the operation year. Furthermore, the frequency of LPSP with the proposed method is larger than the base cases in the LPSP interval of $[0,0.5)$, reflecting the number of days in which the LPSP accounts 50\% more in the proposed cases than in base cases. However, the frequency of LPSP shows inverse results in the interval of $[0.8,1]$, especially in the interval of $[0.9,1]$, in which the base cases show a larger frequency of LPSP than the proposed cases. A large value of LPSP indicates that there is a large gap between the power generated by the HRES and the load power for these days. Therefore, the proposed cases showed a smaller number of days in which the LPSP is greater than 0.8 compared with the base cases. 


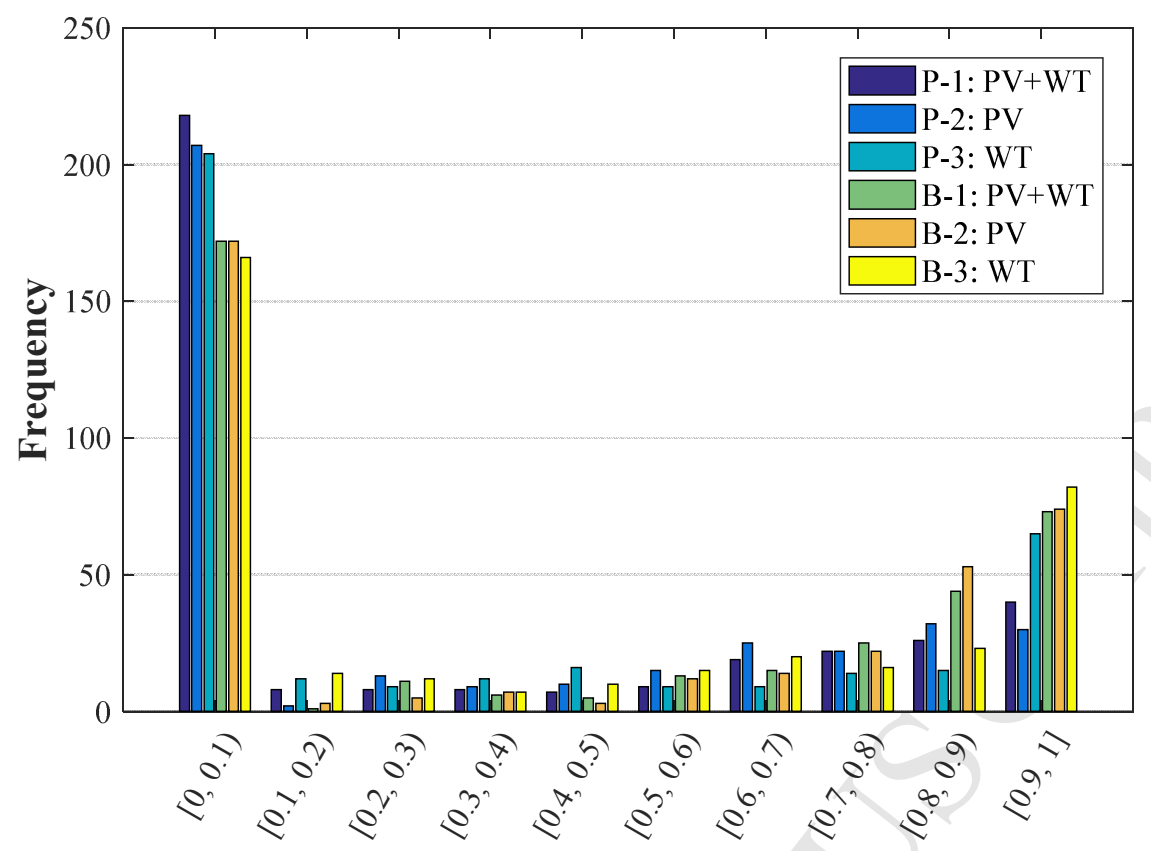

Fig. 9. The histogram of daily LPSPs for different scenarios.

As shown in Fig. S2, the electricity sources, and demand exhibited seasonal variation.

Therefore, the LPSP for each month was also computed considering the reliability changes for the three designed cases in different months. To explain the monthly results of the LPSP in each case in detail, we constructed a Gaussian curve with the mean value and variance value calculated from the hourly LPSP to illustrate the probability density of LPSPs in each month. The underlying distribution of LPSPs for six cases is depicted in Fig. S3. The lighter colors in the figures represent the result of LPSPs in warmer seasons, and the darker colors indicate half of the cold weather season.

In general, the LPSPs during cold weather months (from January to March, November, and December) have larger mean values compared with the warm months, as illustrated in the right part of the figure in both the proposed and base cases. These results can also reflect that the HRES as the electricity supply source is more reliable in warmer seasons than in colder 
season. Comparing the probability density of the LPSP for each month, it can be observed that the probability density in winter (darker color lines) and summer (lighter color lines) from high to low of each scenario following the order as: only PV, integrated PV and WT, and only WT for both of proposed and base cases. This tendency is due to the characteristics of the observed weather conditions and water consumption used in this study.

The water consumption of the measured data from Home Office concentrated, and the solar energy during daytime is are more regular than wind energy considering daily and seasonal patterns. In summer, solar energy shows a high level which can easily satisfy the electricity demand. However, during winter, the solar radiation is low, and the energy supplied by PV system neglects to satisfy the electricity demand. Therefore, if the RES consists of solar energy, the reliability will show a defined variance, locating this parameter at low and high values in for summer and winter seasons, respectively.

\subsection{A new energy reliability index}

During the operation of the HRES, there are several events that may cause shutdowns, resulting in power supply loss. For individual PV modules, the total failure rate is $7.11 \times 10^{-6}$ per hour. Considering the mean downtime of each event, the total annual potential downtime is 0.63 day; moreover, for individual wind turbines, the total failure rate is $4.34 \times 10^{-6}$ per hour. Additionally, the total annual potential downtime is 2.18 days. The annual potential downtime is illustrated in Fig. 10, based on the RES combination for the three scenarios in both the proposed and base cases. Therefore, a new energy reliability index was suggested for the case when the power supply is lost. 


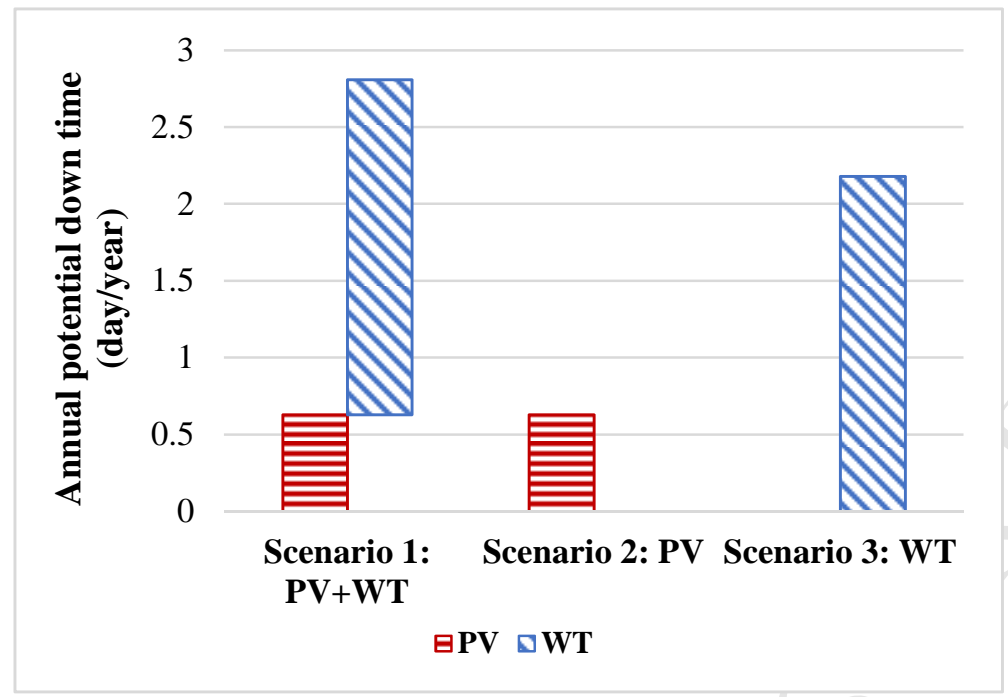

Fig. 10. The annual potential downtime of three RES scenarios.

The value of PLPSP needs to be considered as an important index to estimate the energy reliability for designing the HRES in future conditions, as this value reflects a realistic system considering the failure events that the equipment may present. The PLPSP values of the proposed and base cases are shown in Fig. 11, over a whole year of operation. Contrary to the value of the LPSP, a new index (PLPSP) provides a more realistic metric since it is based on the failure event distribution for each individual piece of equipment. In the first scenario with the hybridization of solar and wind power systems, the PLPSP of the proposed case is 0.4653 , showing an $18.3 \%$ reduction in comparison to the base case (PLPSP $=0.6484)$. For the second and third scenarios with a single RES power source, the PLPSPs for proposed cases represent reductions of $18.9 \%$ and $7.7 \%$ in comparison to the base cases, respectively. The values of PLPSP for the proposed cases are lower than the base cases, which indicates that the performance of an RES is more reliable when we consider future uncertainties via forecasting models. Moreover, the energy storage/supply trade-off becomes controllable and 
schedulable for future unexpected events.

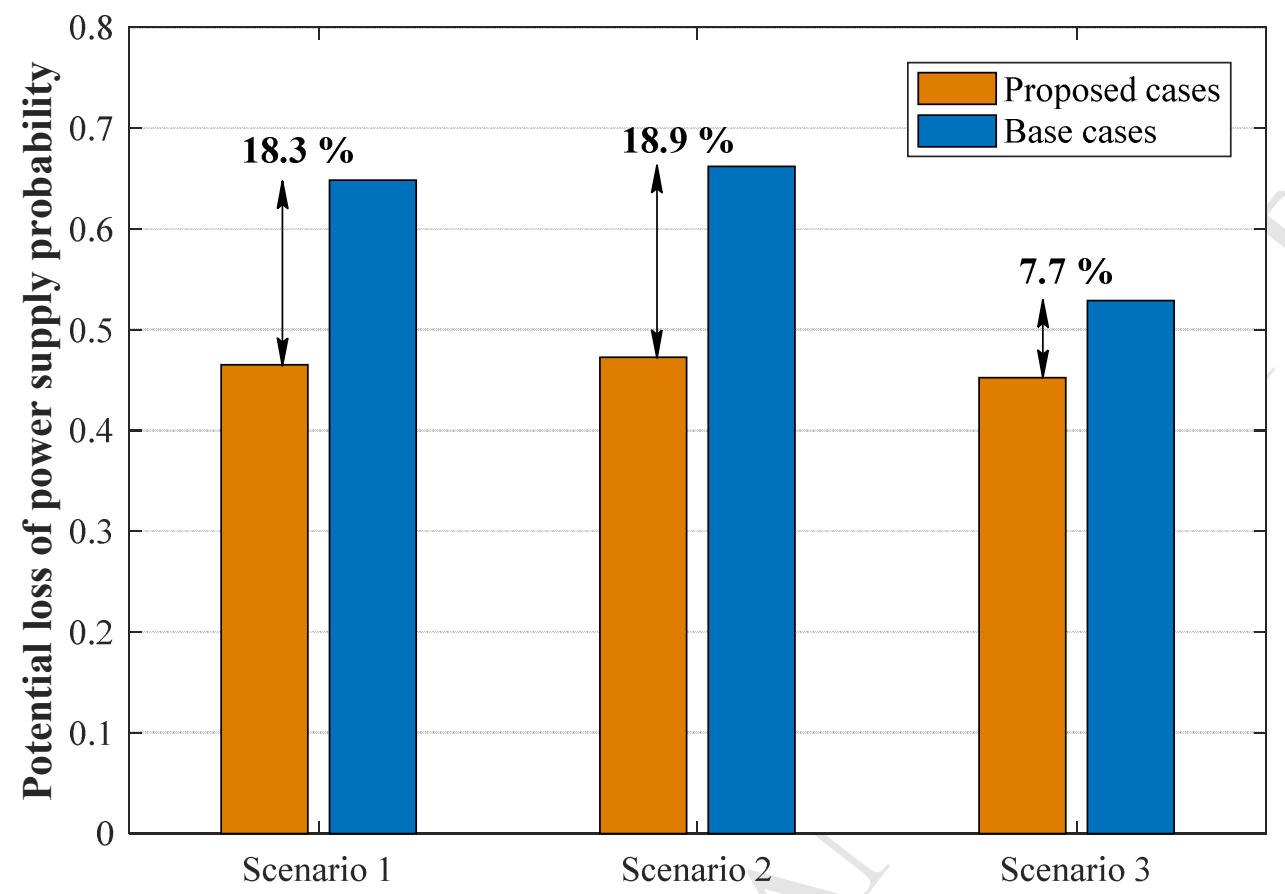

Fig. 11. The potential loss of power supply probability for the proposed case and base case.

A plot of TAC against the PLPSP for the six analyzed cases is shown in Fig. 12. The base cases with lower TAC values have higher PLPSP values located at the upper left corner of the figure. On the contrary, the proposed cases are on the lower right corner, performing higher TAC, and lower PLPSP values. It should be noted that the proposed cases show a lower probability of losing power since the anticipation of the availability of renewable sources and water demand are given by the forecasting models. This provides a more controllable schema for the energy storage and supply to the RO. Considering the aspects of TAC and PLPSP; case P-1, which consists of the hybridization of the renewable sources, outperforms the base cases by approximately $18 \%$ based on reliability and the standalone RESs by about $26 \%$ based on the TAC, as shown as a red star in Fig. 12. 


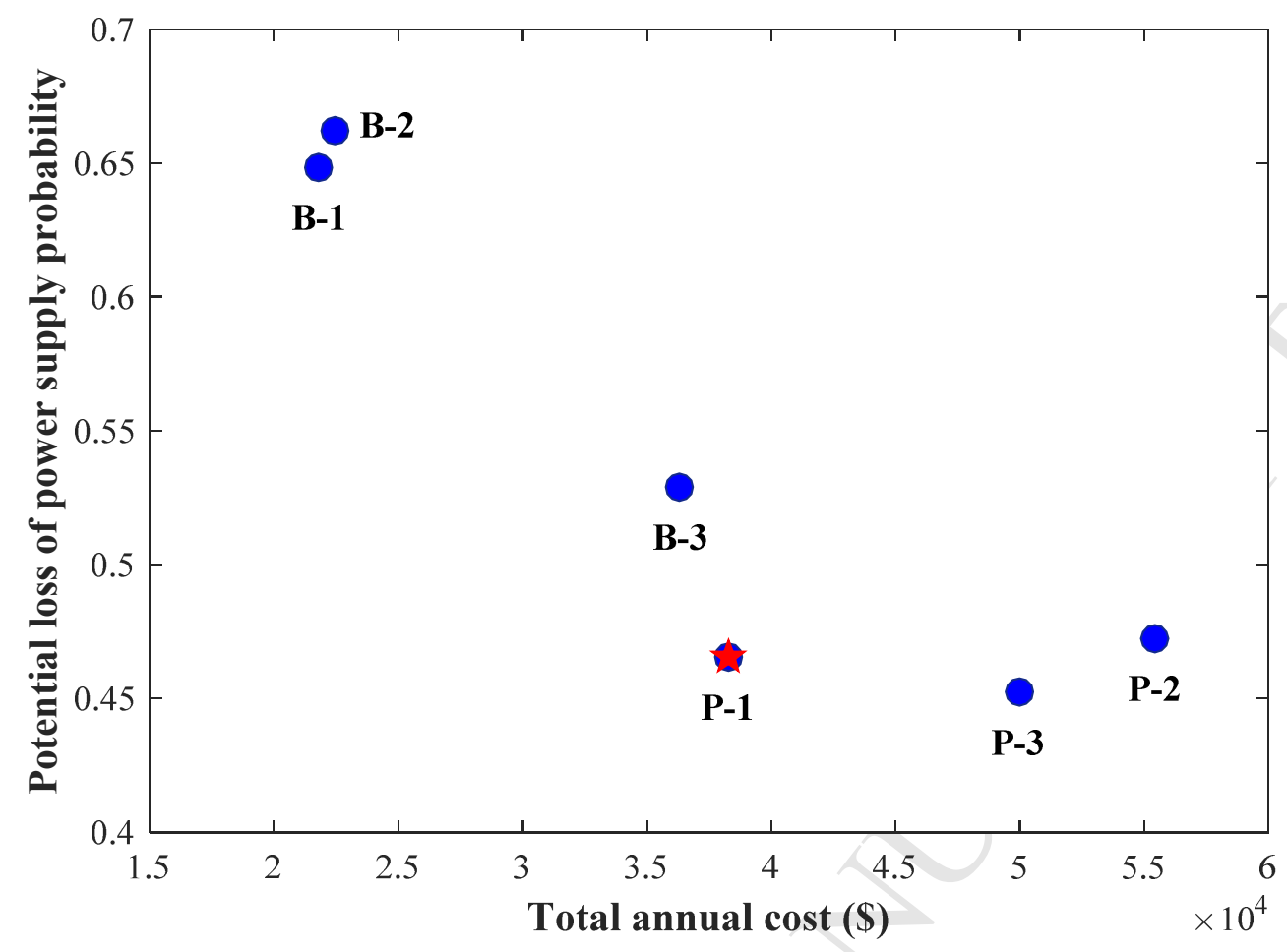

Fig. 12. The relationship between TAC and potential loss of power supply probability of six cases.

\section{Conclusions}

In this study, different RNN structures were implemented to forecast future sequences of weather conditions, and freshwater demand; with the purpose of managing the power supply chain to the integrated HRES-RO desalination system. Then, the multi-objective EMP method was utilized to define the optimal size of the HRES by means of multi-objective aspects including the total annual costs, and GHG emissions. Finally, a power reliability index was introduced to assess the probability of shutdown events during the operability of the scenarios. The scenarios that were introduced to these analyses consisted of forecasted cases, i.e., considering future uncertainties in the power supply chain, and the base cases, which neglected the forecasting model. The findings of the analyses are summarized below: 
1) Meaningful forecasting models were carried out by using different RNN structures coupled with memory cells (i.e., LSTM and GRU), which can process the trends from the components of the power supply chain to forecast future sequences, supporting the design of HRES with future uncertainties consideration.

2) Considering a multi-objective criterion (i.e., economic and environmental effects), the optimal size of the RES was determined for six cases with similar GHG emissions. The base case B-1, which considered the hybridization of solar and wind energy sources, outperformed the other cases with the lowest TAC, which is 21,808 US\$. However, the freshwater provided by resulting the HRES-RO system suffered from a larger shortage to meet the consumer demand, making this system unreliable to satisfy the supply chain.

3) A new energy reliability index that considers the loss of power supply caused by shutdown failure events (PLPSP) was introduced in this study. The cases that employed the RNN-based forecast model outperformed the base cases in terms of reliability; showing that the PLPSPs were reduced $18.3 \%, 18.7 \%$, and $7.7 \%$ for three RES scenarios in the proposed cases compared with the base cases. Moreover, the proposed case study P-1 outperformed the other cases considering the multiple criteria (environmental effect, economic cost, and energy reliability).

This study demonstrated the effectiveness of introducing advanced forecasting methods such as RNN structures to the design of RES. The anticipation of the energy source availability and the dynamic water demand allowed the system to manage prospective power losses, tackling these future variations/uncertainties through a schema of power supply-demand take-off related to the BSS incorporated into the system. 


\section{Nomenclature}
$\mathrm{AC}$
Alternating current
ACC
Annual capital cost
$\mathrm{AF}$
Amortization factor
AI
Artificial intelligence
ANN
Artificial neural networks
AOMC
Annual operating and maintenance cost
ARMA
Autoregressive moving average
BSS
Battery storage system
$\mathrm{CC}$
Capital cost
DC
Direct current
EMP
Extended mathematical programming
EMS
Energy management strategy
GA
Genetic algorithm
GHG
Greenhouse gas
GRU
Gated recurrent unit
HRE
Hybrid renewable energy
HRES
Hybrid renewable energy system
HRES-RO
Integration of hybrid renewable energy system and RO
HSS
Hammersley sequence sampling
LPSP
Loss of power supply probability
LSTM
Long short-term memory
LT
Lifetime of HRES components
MOO
Multi-objective optimization
$\mathrm{OMC}$
Operating and maintenance costs
PLPSP
Potential loss of power supply probability
PSO
Particle swarm optimization
PV
Photovoltaic
RE
Renewable energy
RES
Renewable energy system 


$\begin{array}{ll}\text { RMSE } & \text { Root mean square error } \\ \text { RNN } & \text { Recurrent neural network } \\ \text { RO } & \text { Reverse osmosis } \\ \text { SA } & \text { Simulated annealing } \\ \text { TAC } & \text { Total annual cost } \\ \text { WT } & \text { Wind turbine } \\ f & \text { Operation and maintenance coefficient } \\ i r & \text { Interest rate } \\ \alpha & \text { Battery self-discharge rate } \\ \delta & \text { Battery charge and discharge efficiency } \\ \lambda & \text { Electricity converter efficiency }\end{array}$

\section{Acknowledgments}

This work was supported by a National Research Foundation of Korea (NRF) grant funded by the Korean government (MSIP) (No.2017R1E1A1A03070713).

\section{References}

[1] Shemer H, Semiat R. Sustainable RO desalination - Energy demand and environmental impact. Desalination 2017;424:10-6. doi:https://doi.org/10.1016/j.desal.2017.09.021.

[2] Haidari AH, Heijman SGJ, van der Meer WGJ. Optimal design of spacers in reverse osmosis. Sep Purif Technol 2018;192:441-56. doi:https://doi.org/10.1016/j.seppur.2017.10.042. 
[3] Fragkou MC, McEvoy J. Trust matters: Why augmenting water supplies via desalination may not overcome perceptual water scarcity. Desalination 2016;397:1-8. doi:https://doi.org/10.1016/j.desal.2016.06.007.

[4] Elimelech M, Phillip WA. The Future of Seawater Desalination: Energy, Technology, and the Environment. Science (80- ) 2011;333:712 LP-717. doi:10.1126/science.1200488.

[5] Meerganz von Medeazza G. Water desalination as a long-term sustainable solution to alleviate global freshwater scarcity? A North-South approach. Desalination 2004;169:287-301. doi:https://doi.org/10.1016/j.desa1.2004.04.001.

[6] Safder U, Ifaei P, Rashidi Z, Yoo C. Availability and Reliability of the Integrated Reverse Osmosis-Forward Osmosis Desalination Network. 2017.

[7] Al-falahi MDA, Jayasinghe SDG, Enshaei H. A review on recent size optimization methodologies for standalone solar and wind hybrid renewable energy system. Energy Convers Manag 2017;143:252-74. doi:https://doi.org/10.1016/j.enconman.2017.04.019.

[8] Li Q, Moya W, Janghorban Esfahani I, Rashidi J, Yoo C. Integration of reverse osmosis desalination with hybrid renewable energy sources and battery storage using electricity supply and demand-driven power pinch analysis. Process Saf Environ Prot 2017;111:795-809. doi:https://doi.org/10.1016/j.psep.2017.09.009.

[9] Askarzadeh A, dos Santos Coelho L. A novel framework for optimization of a grid independent hybrid renewable energy system: A case study of Iran. Sol Energy 2015;112:383-96. doi:10.1016/J.SOLENER.2014.12.013. 
[10] Sawle Y, Gupta SC, Bohre AK. Socio-techno-economic design of hybrid renewable energy system using optimization techniques. Renew Energy 2018;119:459-72. doi:10.1016/J.RENENE.2017.11.058.

[11] Yang H, Wei Z, Chengzhi L. Optimal design and techno-economic analysis of a hybrid solar-wind power generation system. Appl Energy 2009;86:163-9. doi:https://doi.org/10.1016/j.apenergy.2008.03.008.

[12] Janghorban Esfahani I, Ifaei P, Kim J, Yoo C. Design of Hybrid Renewable Energy Systems with Battery/Hydrogen storage considering practical power losses: A MEPoPA (Modified Extended-Power Pinch Analysis). Energy 2016;100:40-50. doi:https://doi.org/10.1016/j.energy.2016.01.074.

[13] Zhao J, Guo Z-H, Su Z-Y, Zhao Z-Y, Xiao X, Liu F. An improved multi-step forecasting model based on WRF ensembles and creative fuzzy systems for wind speed. Appl Energy 2016;162:808-26. doi:10.1016/J.APENERGY.2015.10.145.

[14] El Mghouchi Y, Chham E, Krikiz MS, Ajzoul T, El Bouardi A. On the prediction of the daily global solar radiation intensity on south-facing plane surfaces inclined at varying angles. $\quad$ Energy $\quad$ Convers 2016;120:397-411. doi:10.1016/J.ENCONMAN.2016.05.005.

[15] Safder U, Ifaei P, Nam K, Rashidi J, Yoo CK. Availability and reliability analysis of integrated reverse osmosis - Forward osmosis desalination network. Desalin Water Treat 2018;109. doi:10.5004/dwt.2018.22147.

[16] Janghorban Esfahani I, Lee S, Yoo C. Extended-power pinch analysis (EPoPA) for integration of renewable energy systems with battery/hydrogen storages. Renew 
Energy 2015;80:1-14. doi:https://doi.org/10.1016/j.renene.2015.01.040.

[17] Janghorban Esfahani I, Yoo C. An optimization algorithm-based pinch analysis and GA for an off-grid batteryless photovoltaic-powered reverse osmosis desalination system. Renew Energy 2016;91:233-48. doi:https://doi.org/10.1016/j.renene.2016.01.049.

[18] Ming M, Wang R, Zha Y, Zhang T. Multi-Objective Optimization of Hybrid Renewable Energy System with Load Forecasting. 2017 IEEE Int. Conf. Energy Internet, 2017, p. 113-8. doi:10.1109/ICEI.2017.27.

[19] Huang J, Boland J. Performance Analysis for One-Step-Ahead Forecasting of Hybrid Solar and Wind Energy on Short Time Scales. Energies 2018;11:1119.

[20] Gupta RA, Kumar R, Bansal AK. BBO-based small autonomous hybrid power system optimization incorporating wind speed and solar radiation forecasting. Renew Sustain Energy Rev 2015;41:1366-75. doi:https://doi.org/10.1016/j.rser.2014.09.017.

[21] Behzadi Forough A, Roshandel R. Multi objective receding horizon optimization for optimal scheduling of hybrid renewable energy system. Energy Build 2017;150:58397. doi:10.1016/J.ENBUILD.2017.06.031.

[22] Liu H, Mi X, Li Y. Wind speed forecasting method based on deep learning strategy using empirical wavelet transform, long short term memory neural network and Elman neural network. Energy Convers Manag 2018;156:498-514.

[23] Loy-Benitez J, Vilela P, Li Q, Yoo CK. Sequential prediction of quantitative health risk assessment for the fine particulate matter in an underground facility using deep recurrent neural networks. Ecotoxicol Environ Saf 2019;169:316-24. doi:10.1016/j.ecoenv.2018.11.024. 
[24] El Fathi A, Outzourhit A. Technico-economic assessment of a lead-acid battery bank for standalone photovoltaic power plant. J Energy Storage 2018;19:185-91. doi:https://doi.org/10.1016/j.est.2018.07.019.

[25] El-Emam RS, Dincer I. Investigation and assessment of a novel solar-driven integrated energy system. Energy Convers Manag 2018;158:246-55. doi:10.1016/J.ENCONMAN.2017.12.062.

[26] Cabrera P, Carta JA, González J, Melián G. Wind-driven SWRO desalination prototype with and without batteries: A performance simulation using machine learning models. Desalination 2018;435:77-96. doi:10.1016/J.DESAL.2017.11.044.

[27] Kabalci E. Design and analysis of a hybrid renewable energy plant with solar and wind power. $\quad$ Energy Convers Manag 2013;72:51-9. doi:10.1016/J.ENCONMAN.2012.08.027.

[28] Prasad AR, Natarajan E. Optimization of integrated photovoltaic-wind power generation systems with battery storage. Energy 2006;31:1943-54. doi:10.1016/J.ENERGY.2005.10.032.

[29] Rajkumar RK, Ramachandaramurthy VK, Yong BL, Chia DB. Techno-economical optimization of hybrid pv/wind/battery system using Neuro-Fuzzy. Energy 2011;36:5148-53. doi:10.1016/J.ENERGY.2011.06.017.

[30] Wei-Chiang H. Hybrid Advanced Optimization Methods with Evolutionary Computation Techniques in Energy Forecasting. MDPI; 2018. doi:10.3390/books978-3-03897-287-7.

[31] Faccio M, Gamberi M, Bortolini M, Nedaei M. State-of-art review of the optimization 
methods to design the configuration of hybrid renewable energy systems (HRESs). Front Energy 2018;12:591-622. doi:10.1007/s11708-018-0567-x.

[32] Olatomiwa L, Mekhilef S, Ismail MS, Moghavvemi M. Energy management strategies in hybrid renewable energy systems: A review. Renew Sustain Energy Rev 2016;62:821-35. doi:10.1016/J.RSER.2016.05.040.

[33] Chauhan A, Saini RP. Techno-economic optimization based approach for energy management of a stand-alone integrated renewable energy system for remote areas of India. Energy 2016;94:138-56. doi:10.1016/J.ENERGY.2015.10.136.

[34] Nag AK, Sarkar S. Modeling of hybrid energy system for futuristic energy demand of an Indian rural area and their optimal and sensitivity analysis. Renew Energy 2018;118:477-88. doi:10.1016/J.RENENE.2017.11.047.

[35] Rajbongshi R, Borgohain D, Mahapatra S. Optimization of PV-biomass-diesel and grid base hybrid energy systems for rural electrification by using HOMER. Energy 2017;126:461-74. doi:10.1016/J.ENERGY.2017.03.056.

[36] Ekren O, Ekren BY. Size optimization of a PV/wind hybrid energy conversion system with battery storage using simulated annealing. Appl Energy 2010;87:592-8. doi:10.1016/J.APENERGY.2009.05.022.

[37] Chen H, Yang C, Deng K, Zhou N, Wu H. Multi-objective optimization of the hybrid wind/solar/fuel cell distributed generation system using Hammersley Sequence Sampling. Int J Hydrogen Energy 2017;42:7836-46. doi:10.1016/J.IJHYDENE.2017.01.202.

[38] Chang K-H, Lin G. Optimal design of hybrid renewable energy systems using 
simulation optimization. Simul Model Pract Theory 2015;52:40-51. doi:10.1016/J.SIMPAT.2014.12.002.

[39] Kamjoo A, Maheri A, Dizqah AM, Putrus GA. Multi-objective design under uncertainties of hybrid renewable energy system using NSGA-II and chance constrained programming. Int J Electr Power Energy Syst 2016;74:187-94. doi:https://doi.org/10.1016/j.ijepes.2015.07.007.

[40] Wang L, Singh C. Multicriteria Design of Hybrid Power Generation Systems Based on a Modified Particle Swarm Optimization Algorithm. IEEE Trans Energy Convers 2009;24:163-72. doi:10.1109/TEC.2008.2005280.

[41] Kyriakarakos G, Dounis AI, Arvanitis KG, Papadakis G. A fuzzy logic energy management system for polygeneration microgrids. Renew Energy 2012;41:315-27. doi:10.1016/J.RENENE.2011.11.019.

[42] Dolara A, Grimaccia F, Leva S, Mussetta M, Ogliari E. A physical hybrid artificial neural network for short term forecasting of PV plant power output. Energies 2015;8:1138-53. doi:10.3390/en8021138.

[43] Macedo MNQ, Galo JJM, de Almeida LAL, de C. Lima AC. Demand side management using artificial neural networks in a smart grid environment. Renew Sustain Energy Rev 2015;41:128-33. doi:10.1016/J.RSER.2014.08.035.

[44] Mitchell M. An introduction to genetic algorithms. MIT press; 1998.

[45] Rini DP, Shamsuddin SM, Yuhaniz SS. Particle swarm optimization: technique, system and challenges. Int J Comput Appl 2011;14:19-26.

[46] Bordin C, Anuta HO, Crossland A, Gutierrez IL, Dent CJ, Vigo D. A linear 
programming approach for battery degradation analysis and optimization in offgrid power systems with solar energy integration. Renew Energy 2017;101:417-30. doi:10.1016/J.RENENE.2016.08.066.

[47] Shahzad MW, Burhan M, Ang L, Ng KC. Energy-water-environment nexus underpinning future desalination sustainability. Desalination 2017;413:52-64. doi:https://doi.org/10.1016/j.desal.2017.03.009.

[48] Kaboli SHA, Selvaraj J, Rahim NA. Long-term electric energy consumption forecasting via artificial cooperative search algorithm. Energy 2016;115:857-71. doi:10.1016/j.energy.2016.09.015.

[49] Kaboli SHA, Fallahpour A, Kazemi N, Selvaraj J, Rahim NA. An Expression-Driven Approach for Long-Term Electric Power Consumption Forecasting. Am J Data Min Knowl Discov 2016;1:16-28. doi:10.11648/j.ajdmkd.20160101.13.

[50] Kaboli SHA, Fallahpour A, Selvaraj J, Rahim NA. Long-term electrical energy consumption formulating and forecasting via optimized gene expression programming. Energy 2017;126:144-64. doi:10.1016/j.energy.2017.03.009.

[51] Amrollahi MH, Bathaee SMT. Techno-economic optimization of hybrid photovoltaic/wind generation together with energy storage system in a stand-alone micro-grid subjected to demand response. Appl Energy 2017;202:66-77. doi:10.1016/j.apenergy.2017.05.116.

[52] Brooke A, Kendrick DA, Meeraus A, Rosenthal RE. GAMS: A user's guide: Course Technology. 1988.

[53] Mavrotas G. Generation of efficient solutions in Multiobjective Mathematical 
Programming problems using GAMS. Effective implementation of the $\varepsilon$-constraint method. Lect Lab Ind Energy Econ Sch Chem Eng Natl Tech Univ Athens 2007.

[54] Li Y, Wu H, Liu H. Multi-step wind speed forecasting using EWT decomposition, LSTM principal computing, RELM subordinate computing and IEWT reconstruction. Energy Convers Manag 2018;167:203-19.

[55] Li Y, Shi H, Han F, Duan Z, Liu H. Smart wind speed forecasting approach using various boosting algorithms, big multi-step forecasting strategy. Renew Energy 2019;135:540-53. doi:10.1016/J.RENENE.2018.12.035.

[56] Shu Z, Jirutitijaroen P. Latin hypercube sampling techniques for power systems reliability analysis with renewable energy sources. IEEE Trans Power Syst 2011;26:2066-73.

[57] Bhandari B, Lee K-T, Lee G-Y, Cho Y-M, Ahn S-H. Optimization of hybrid renewable energy power systems: A review. Int J Precis Eng Manuf Technol 2015;2:99-112.

[58] Maleki A. Design and optimization of autonomous solar-wind-reverse osmosis desalination systems coupling battery and hydrogen energy storage by an improved bee algorithm. Desalination 2018;435:221-34. doi:https://doi.org/10.1016/j.desal.2017.05.034.

[59] Peng W, Maleki A, Rosen MA, Azarikhah P. Optimization of a hybrid system for solar-wind-based water desalination by reverse osmosis: Comparison of approaches. Desalination 2018;442:16-31. doi:https://doi.org/10.1016/j.desal.2018.03.021.

[60] Chiacchio F, D’Urso D, Aizpurua JI, Compagno L. Performance assessment of domestic photovoltaic power plant with a storage system. 16th IFAC Symp. Inf. 
Control Probl. Manuf., 2018.

[61] Pfaffel S, Faulstich S, Rohrig K. Performance and Reliability of Wind Turbines: A Review. Energies 2017;10:1904. doi:10.3390/en10111904.

[62] Fetanat A, Khorasaninejad E. Size optimization for hybrid photovoltaic-wind energy system using ant colony optimization for continuous domains based integer programming. Appl Soft Comput 2015;31:196-209. doi:https://doi.org/10.1016/j.asoc.2015.02.047.

[63] Ramli MAM, Hiendro A, Twaha S. Economic analysis of PV/diesel hybrid system with flywheel energy storage. Renew Energy 2015;78:398-405. doi:https://doi.org/10.1016/j.renene.2015.01.026.

[64] Brander M, Sood A, Wylie C, Haughton A, Lovell J. Technical Paper| Electricity-specific emission factors for grid electricity. Ecometrica, Emiss Com 2011.

[65] Hondo H. Life cycle GHG emission analysis of power generation systems: Japanese case. Energy 2005;30:2042-56.

[66] Mohammad Rozali NE, Wan Alwi SR, Abdul Manan Z, Klemeš JJ, Hassan MY. Process integration of hybrid power systems with energy losses considerations. Energy 2013;55:38-45. doi:10.1016/j.energy.2013.02.053.

[67] Bedi J, Toshniwal D. Deep learning framework to forecast electricity demand. Appl Energy 2019;238:1312-26. doi:10.1016/j.apenergy.2019.01.113.

[68] Hwangbo S, Nam KJ, Heo SK, Yoo CK. Hydrogen-based self-sustaining integrated renewable electricity network (HySIREN) using a supply-demand forecasting model and deep-learning algorithms. Energy Convers Manag 2019;185:353-67. 
doi:10.1016/j.enconman.2019.02.017. 


\section{Research Highlights}

- An integrated HRES and RO system with battery storage is designed and optimized.

- The future supply chain is forecasted by variant RNN structures.

- Multi-criteria optimization is conducted using extended mathematical programming.

- The PLPSP is introduced to estimate the sustainability of the designed system.

- The proposed method shows significant advantages to address future uncertainties. 